\title{
A simple reverse genetics method to generate recombinant coronaviruses
}

Julien Mélade ( $\nabla$ julien.melade@hotmail.fr)

Unité des Virus Émergents

Géraldine Piorkowski

Aix-Marseille University

Franck Touret

UVE Aix Marseille Univ, IRD 190, INSERM 1207, IHU Méditerranée Infection https://orcid.org/00000002-4734-2249

\section{Toscane Fourié}

Unité des Virus Émergents

Jean-Sélim Driouich

Unité des Virus Émergents

Maxime Cochin

Unité des Virus Émergents

Hawa Sophia Bouzidi

Unité des Virus Émergents

Bruno Coutard

Unité des Virus Émergents

Antoine Nougairède

Unité des Virus Émergents

Xavier de Lamballerie

Unité des Virus Émergents

\section{Research Article}

Keywords: SARS-CoV-2, ISA, mCherry, in vivo, serology, antiviral

Posted Date: March 9th, 2021

DOl: https://doi.org/10.21203/rs.3.rs-59766/v3

License: (9) (i) This work is licensed under a Creative Commons Attribution 4.0 International License. Read Full License 
Version of Record: A version of this preprint was published at EMBO reports on March 3rd, 2022. See the published version at https://doi.org/10.15252/embr.202153820. 


\section{Title}

2 A simple reverse genetics method to generate recombinant coronaviruses

\section{Authors}

4 Julien Mélade*, Géraldine Piorkowski, Franck Touret, Toscane Fourié, Jean-Sélim Driouich, 5 Maxime Cochin, Hawa Sophia Bouzidi, Bruno Coutard, Antoine Nougairède \& Xavier de $6 \quad$ Lamballerie.

$7 \quad *$ Corresponding author

$8 \quad$ julien.melade@univ-amu.fr

\section{$9 \quad$ Affiliation}

10 Unité des Virus Émergents (UVE: Aix-Marseille Univ-IRD 190-Inserm 1207), Marseille, 11 France. 
Engineering recombinant viruses is capital for deciphering the biology of emerging viral pathogens such as the severe acute respiratory syndrome coronavirus 2 (SARS-CoV-2). However, the large size of coronaviruses genome makes reverse genetics methods challenging. Here we describe a simple method based on "infectious subgenomic amplicons" (ISA) technology to generate recombinant infectious coronaviruses with no need for reconstructing a full genomic cDNA. The method was applied to the SARS-CoV-2 and the feline enteric coronavirus, and allowed to rescue wild-type viruses with biological characteristics closely similar to original strains. Mutations and fluorescent red reporter gene were rapidly incorporated into the SARS-CoV-2 genome allowing the generation of a genomic variant and a fluorescent reporter strains which were studied during in vivo experiments, serological diagnosis and antiviral assays. The swiftness and simplicity of the ISA method has the potential to facilitate the advance of coronavirus reverse genetics studies and to explore biological properties of SARS-CoV-2 variants or accelerating the development of therapeutic measures. 


\section{Introduction}

The order Nidovirales represents a large group of single-stranded positive-sense RNA viruses $((+)$ ssRNA) characterized by the size of their genomes, which are the largest among the RNA viruses. This order is subdivided into nine suborders including Cornidovirineae in which is found the Coronaviridae family. Coronaviruses (CoVs) have a wide range of hosts including humans, domestic and wild animals.

The severe acute respiratory syndrome coronavirus 2 (SARS-CoV-2; genus: Betacoronavirus) which emerged in 2019 in Wuhan, is responsible for COVID-19, a disease that has been associated in a proportion of patients with a severe pneumonia leading to respiratory distress and possibly to death ${ }^{1,2}$. SARS-CoV-2 has spread worldwide with more than 67 million people being infected by the end 2020. In the course of the pandemic, a European variant carrying an amino acid change in the spike protein (D614G) rapidly dispersed worldwide and became the most prevalent and dominant pandemic strain ${ }^{3}$. Later in 2020, others variants were detected in Denmark $^{4}$, South East England ${ }^{5}$, Brazil ${ }^{6}$ and South Africa ${ }^{7}$. The emergence of these variants raised questions concerning the possibility of viral escape from the immune response induced following either primary infection, vaccination or therapeutics applied as convalescent plasma ${ }^{8}$. The ongoing emergence of variants, their circulation and the genetic diversity observed in $\mathrm{CoV}$ populations highlight the need for convenient molecular tools to study viral evolution, replication, and pathogenesis and to enable the development of appropriate health control countermeasures.

Reverse genetics methods enable the engineering of wild-type or genetically modified CoVs and thus can contribute to deciphering biological properties of human or animal viruses ${ }^{9,10}$. In addition, they can be used to expedite antiviral screening for the selection and characterization of small antiviral molecules or therapeutic antibodies ${ }^{11}$. In the case of CoVs, rescue of infectious viruses can be obtained by the transfection of full-length cDNAs using vaccinia virus vectors or bacterial artificial chromosomes ${ }^{10,12-14}$. Alternatively, in vitro or in-yeast viral genome assembly followed by in vitro RNA production can lead to rescue viruses by transfection of full-length cDNAs in cells ${ }^{15,16}$. However, due to the complexity and large size of CoV genomes, the assembly and modification of full-length genomic cDNAs or RNAs remains laborious, technically difficult to reproduce and time-consuming (e.g. toxicity of clones, difficulty in constructing precise full-length $30 \mathrm{~kb}$ RNA transcripts in vitro). 
The Infectious Subgenomic Amplicons (ISA) method is a simple and rapid bacterium-free method that has been developed in recent years for viruses with relatively short (+) ssRNA genomes, such as members of the Flaviviridae, Togaviridae and Picornaviridae families ${ }^{17-21}$. With the ISA method, wild-type and genetically modified infectious viruses can be recovered within days where conventional reverse genetics systems require additional cloning steps or in vitro manipulation of the RNA molecules. The ISA method is based on the simple transfection of overlapping subgenomic DNA fragments, encompassing the entire virus genome into permissive cells. DNA recombination and production of full-length viral genomic RNA, under transcription signals, are accomplished by the cellular machinery.

In the current study, we rescued the wild-type European variant of SARS-CoV-2 and the feline enteric coronavirus $(\mathrm{FeCoV})$, a ubiquitous veterinary pathogen commonly circulating in felid populations and responsible for common enteritis ${ }^{22}$ and the severe systemic disease, feline infectious peritonitis (FIP) ${ }^{23}$. We derived the original D614 coding sequence of the Wuhan SARS-CoV-2 by mutagenesis and added a mCherry fluorescent reporter gene. The characterization of each rescued strains performed in vitro and in a golden Syrian hamster model for SARS-CoV-2, and seroneutralization tests and antiviral assays were conducted using the mCherry fluorescent SARS-CoV-2 strain. Our results demonstrated the suitability of the strategy to study biological properties of viruses engineered using the ISA method. 


\section{Materials and Methods}

Cells.

Baby Hamster Kidney 21 cells (BHK-21; ATCC CCL-10) were grown in Minimal Essential Medium (MEM; Life Technologies) with 5\% heat-inactivated foetal calf serum (FCS), 1\% Lglutamine (200mM; Life Technologies), 5\% Tryptose Phosphate Broth (TPB; Life Technologies) and 1\% Penicillin/Streptomycin (P/S; $5000 \mathrm{U} / \mathrm{mL} ; 5 \mathrm{mg} / \mathrm{mL})$. VeroE6 cells (ATCC CRL-1586) were grown in MEM supplemented with 5\% FCS, 1\% L-glutamine, 1\% $\mathrm{P} / \mathrm{S}$ and $1 \%$ non-essential amino acids (NEAA; Life Technologies). Feline embryonic fibroblast cells (FeA) were grown in Dulbecco's Modified Eagle Medium (DMEM; Life Technologies) with $10 \%$ FCS and 1\% P/S. Feline pulmonary epithelial cells (AK-D; ATCC CCL-150) were grown in a mix of Ham's F12 (F12) and Leibovitz's (L-15) mediums (v/v) with 7\% FCS and $1 \%$ PS. Cells were grown at $37{ }^{\circ} \mathrm{C}$ in an atmosphere containing $5 \% \mathrm{CO} 2$.

\section{Viral strains.}

A clinical SARS-CoV-2 European strain was provided courtesy of Pr. Christian Drosten (Charité, Berlin) from the European Archive Collection (human isolate BetaCoV/Germany/BavPat1/2020 p.1; reference: 026V-03883). FeCoV was obtained from the American Type Culture Collection (ATCC reference: VR-2126). SARS-CoV-2 and FeCoV clinical samples were first passaged on VeroE6 and FeA respectively. An MOI of 0.001 and 0.01 were used to infect $12.5 \mathrm{~cm} 2$ culture flasks of confluent VeroE6 and FeA cells with the clinical SARS-CoV-2 and FeCoV respectively. Cells were washed twice (HBSS) 1 hour after the infection and $4 \mathrm{~mL}$ of medium was added. Cell supernatant media were sampled at 48 hours post-infection, clarified by centrifugation, aliquoted and stored at $-80^{\circ} \mathrm{C}$. All experiments were conducted in a BSL3 laboratory.

\section{Preparation of subgenomic cDNA fragments.}

Based on full-length sequences, eight overlapping fragments were designed and supplied by the manufacturer (Genscript or Thermo Fisher Scientific). The first and last fragments were directly flanked at their 5' and 3'extremities by the pCMV and the HDR/SV40pA respectively during de novo synthesis. To construct the D614 sequence and according to a Wuhan SARS-CoV-2 genome (Genbank accession number: NC045512), the Glycine (Gly) amino acid (GGT) located at position 614 of the spike protein in the fragment $n^{\circ} 7$ was replaced by an Aspartic acid (Asp) (GAT) and de novo synthesized (Thermo Fisher Scientific). From this construction, we inserted 
a synthetic monomeric red fluorescent protein gene (mCherry) (Genbank accession number: AY678264) downstream of the regulatory sequence of the ORF3a (position 25392 - 26221) which was then de novo synthesized (Thermo Fisher Scientific). cDNAs were amplified from these de novo synthetic viral fragments as templates. A Super Fidelity PCR polymerase kit (Thermo Fisher Scientific) was used. Primer sequences and positions on genome are described in supplemental table 1 . The final mixture contained $25 \mu \mathrm{L}$ of reaction mix, $2 \mu \mathrm{L}$ of DNA ( 1 $\mathrm{ng} / \mu \mathrm{L}), 100 \mathrm{nM}$ of each primer and $20 \mu \mathrm{L}$ nuclease-free water. RT-PCR and PCR reactions were performed on a Biometra TProfessional Standard Gradient thermocycler with the following conditions: $98^{\circ} \mathrm{C}$ for 30 s followed by 35 cycles of $98{ }^{\circ} \mathrm{C}$ for $10 \mathrm{~s}$, for $\mathrm{X}^{\circ} \mathrm{C}$ for $10 \mathrm{~s}$ (Supplemental table 2), $72{ }^{\circ} \mathrm{C}$ for $30 \mathrm{~s} / \mathrm{kb}$ and $72{ }^{\circ} \mathrm{C}$ for $5 \mathrm{~min}$ and a preliminary step of $50{ }^{\circ} \mathrm{C}$ for 30 min for the RT-PCR. Amplicons were purified (Monarch® PCR \& DNA Cleanup Kit; New England Biolabs) and the size of PCR products was verified by gel electrophoresis. All PCR products were sequenced to ensure that the genotypic integrity of each fragment was accurate before transfection.

\section{Cell Transfection.}

An equimolar mix (300 ng) of subgenomic cDNA fragments of SARS-CoV-2 and FeCoV was transfected into 96-wells of subconfluent BHK-21 cells and a coculture of BHK-21 + FeA cells respectively using Lipofectamine 3000 (Thermo Fischer Scientific). Lipofectamine and DNA were incubated for 45 minutes at room temperature and added to cells for 24 hours. These cell lines were selected after testing, in parallel, a panel of conditions (Supplemental table 3). For SARS-CoV-2, a suspension of VeroE6 cells was added 24 hours after transfection and then incubated for 5 days at $37^{\circ} \mathrm{C}$ in $5 \% \mathrm{CO}_{2}$. For $\mathrm{FeCoV}$, fresh medium was added 24 hours after transfection and then incubated for 5 days at $37^{\circ} \mathrm{C}$ in $5 \% \mathrm{CO}_{2}$. Cell supernatant media were harvested and serially passaged 2 times to ensure the complete disappearance of the DNA used during transfection. Passages were performed by inoculating clarified supernatant media onto subconfluent VeroE6 and AK-D cells for SARS-CoV-2 and FeCoV respectively: after $1 \mathrm{~h}$ of incubation, cells were washed twice using Hanks' Balanced Salt solution (HBSS; Gibco), fresh medium was added, and plates were incubated for 2 days. After the last passage, cell supernatant media were harvested, clarified by centrifugation, aliquoted and stored at $-80^{\circ} \mathrm{C}$. These virus stocks were used to perform quantification of viral RNA, TCID 50 assay, sequencing and determination of kinetic reproduction.

\section{Remdesivir antiviral activity on clinical and ISA SARS-CoV-2 strains.}


The antiviral efficacy of Remdesivir on SARS-CoV-2 strains was assessed by determining the $50 \%$ and 90\% effective concentrations (EC50 and EC90) as described in Touret et al., 202025 . Briefly, one day prior to infection, $5 \times 10^{4}$ VeroE6 cells were seeded in $100 \mu \mathrm{L}$ assay medium (containing 2.5\% FCS) in 96 well plates. The next day, eight two-fold serial dilutions of Remdesivir (from 20 to $0.15 \mu \mathrm{M}$, in triplicate (BLDPHARM, Shanghai, China) were added to the cells $(25 \mu \mathrm{L} /$ well, in assay medium). Four virus control wells were supplemented with $25 \mu \mathrm{L}$ of assay medium. After $15 \mathrm{~min}, 25 \mu \mathrm{L}$ of a calibrated virus mix diluted in medium was added to each well. Four cell control wells (i.e. with no virus) were supplemented with $25 \mu \mathrm{L}$ of assay medium. Plates were incubated for 2 days at $37{ }^{\circ} \mathrm{C}$ prior to quantification of the viral genome by real-time RT-PCR as described below. For fluorescence experiments, plates were analyzed on the same day immediately following supernatant medium collection for molecular biology, with the Incucyte ${ }^{\circledR}$ S3 Live-Cell Analysis Systems (Sartorius) according to the manufacturer's instructions, with an acquisition time of $800 \mathrm{~ms}$ for the red channel. The percentage of fluorescent cells from an area was obtained using the Incucyte 2020B software (Sartorius). Dose response curves were generated using GraphPad Prism 7.00. EC50 and EC90 were estimated using logarithmic interpolation also with GraphPad Prism 7.00.

\section{Human sera.}

A total of 24 human sera (leftovers from volunteer donors who consented to non-therapeutic use of blood products) were tested for the presence of SARS-CoV-2 neutralizing antibodies (nAbs). All human sera were heat inactivated at $56^{\circ} \mathrm{C}$ for $30 \mathrm{~min}$ before anonymization and testing.

\section{CPE and fluorescent based neutralization assay}

To determine the level of SARS-CoV-2 nAbs, $110 \mu \mathrm{L}$ of twofold serial-diluted serum was preincubated with $110 \mu \mathrm{L}$ of $1,000 \mathrm{TCID}_{50} / \mathrm{mL}$ of SARS-CoV-2 strains in 5\% FBS in DMEM for $60 \mathrm{~min}$ at $37^{\circ} \mathrm{C}$. The virus-serum mixtures were then added into 96-wells plate of confluent monolayer Vero-E6 cells for 5 days at $37^{\circ} \mathrm{C}$ with $5 \% \mathrm{CO}_{2}$. The neutralization titer was defined as the highest dilution that inhibited the production of distinct CPE with the ISA D614 SARSCoV-2 or fluorescence with the fluorescent mCherry D614 SARS-CoV-2. Samples with nAbs titers $\leq 10$ were considered negative. In any of the duplicate testing wells was observed. The fluorescence signal was recorded using the Incucyte ${ }^{\circledR}$ S3 Live-Cell Analysis Systems (Sartorius) with an acquisition time of $800 \mathrm{~ms}$ for the red channel. 
175 In vivo experiment in a hamster model were performed as previously described ${ }^{26}$. All experiments were approved by the local ethical committee $(\mathrm{C} 2 \mathrm{EA}-14)$ and the French 'Ministère de l'Enseignement Supérieur, de la Recherche et de l'Innovation' (APAFIS\#23975) and performed in accordance with the French national guidelines and the European legislation covering the use of animals for scientific purposes.

Animal handling

Female Syrian hamsters aged three-weeks-old were provided by Janvier Labs. Animals were maintained in ISOcage P - Bioexclusion System (Techniplast) with unlimited access to water/food and 14h/10h light/dark cycle. Every day, animals were weighed and monitored for the duration of the study to detect the appearance of any clinical signs of illness/suffering. Virus inoculation was performed under general anesthesia (isoflurane). Lungs and blood were collected after euthanasia (cervical dislocation) which was also realized under general anesthesia (isofluorane).

Hamster Infection.

Groups of 4 anesthetized animals (four-week-old) were intranasally infected with $50 \mu \mathrm{L}$ containing $10^{3} \mathrm{TCID}_{50}$ of virus in $0.9 \%$ sodium chloride solution. The mock group was intranasally inoculated with $50 \mu \mathrm{L}$ of $0.9 \%$ sodium chloride solution.

Organ collection.

Lung and blood samples were collected immediately after the time of sacrifice. Left pulmonary lobes were first washed in $10 \mathrm{~mL}$ of $0.9 \%$ sodium chloride solution and then transferred to a $2 \mathrm{~mL}$ tube containing $1 \mathrm{~mL}$ of $0.9 \%$ sodium chloride solution and $3 \mathrm{~mm}$ glass beads. They were crushed using the Tissue Lyser machine (Retsch MM400) for $20 \mathrm{~min}$ at 30 cycles/s and then centrifuged $10 \mathrm{~min}$ à $16,200 \mathrm{~g}$. Supernatant media were transferred to a $2 \mathrm{~mL}$ tube, centrifuged $10 \mathrm{~min}$ at $16,200 \mathrm{~g}$ and stored at $-80^{\circ} \mathrm{C}$. One milliliter of blood was harvested in a $2 \mathrm{~mL}$ tube containing $100 \mu \mathrm{L}$ of $0.5 \mathrm{M}$ EDTA (ThermoFischer Scientific). Blood was centrifuged for 10 min at $16,200 \mathrm{~g}$ and stored at $-80^{\circ} \mathrm{C}$.

\section{RT-qPCR assays.}

Viral RNA was isolated from $100 \mu \mathrm{L}$ of cell supernatant medium using a QIAamp Viral RNA kit and RNase-Free DNase Set on the automated QIAcube (Qiagen) facility, following the 
manufacturer's instructions. Relative quantification of viral RNA was performed using the express One-Step SuperScript ${ }^{\circledR}$ RT-qPCR (Invitrogen). To isolate viral RNA from tissues, $100 \mu \mathrm{L}$ of organ clarified homogenates, spiked with $10 \mu \mathrm{L}$ of internal control (bacteriophage $\left.\mathrm{MS}_{2}\right)^{27}$, were transferred into an S-block containing the recommended volumes of VXL, proteinase $\mathrm{K}$ and RNA carrier. The RT-qPCR reaction mixture (for SARS-CoV-2 and MS2 viral genome detection) was processed using the GoTaq Probe 1-Step RT-qPCR kit (Promega) and contained $5 \mu \mathrm{L}$ of Master Mix $2 \mathrm{X}, 0.25 \mu \mathrm{L}$ of each primer $(500 \mathrm{nM}), 0.07 \mu \mathrm{L}$ of probe $(75$ $\mathrm{nM}), 0.2 \mu \mathrm{L}$ of GoScript RT mix, $0.4 \mu \mathrm{L}$ of $\mathrm{H}_{2} \mathrm{O}$ and $3.8 \mu \mathrm{L}$ of extracted nucleic acids. Assays were performed using the QuantStudio 12K Flex Real-Time PCR machine (ThermoFisher Scientific) with the following conditions: $50^{\circ} \mathrm{C}$ for $15 \mathrm{~min}$ and $95^{\circ} \mathrm{C}$ for $2 \mathrm{~min}$, followed by 45 cycles of $95^{\circ} \mathrm{C}$ for $3 \mathrm{~s}$ and $60^{\circ} \mathrm{C}$ for $30 \mathrm{~s}$. Data collection occurred during the $60^{\circ} \mathrm{C}$ step. The amount of viral RNA was calculated from standard curves using synthetic RNA. The primers and probes used are described in supplemental table 4.

\section{Tissue Culture Infectious Dose 50 (TCID50) assay.}

Subconfluent cultures of VeroE6 and AK-D cells in 96-well culture microplates were used for SARS-CoV-2 and FeCoV respectively TCID 50 determination. Cells were inoculated with 100 or $150 \mu \mathrm{L}$ per well of serial dilutions of each sample (four-fold or ten-fold dilutions when analyzing lung clarified homogenates or cell supernatant media respectively) and incubated for 3-6 days for each virus. Each row included 6 wells of the dilution and two negative controls. The presence of CPE in each well was used to determine TCID $50 / \mathrm{mL}$. The determination of the $\mathrm{TCID}_{50} / \mathrm{mL}$ for both viruses was performed using the Reed and Muench method ${ }^{28}$.

\section{Virus replication kinetics.}

Infections at MOIs of 0.001 and 0.01 were performed using subconfluent VeroE6 or AK-D cells for SARS-CoV-2 and FeCoV, respectively. Cells were washed twice (HBSS) for 4 and 1 hours after infection with SARS-CoV-2 and FeCoV respectively and fresh medium was added. Cell supernatant media were sampled every 12 hours for up to 48 hours, clarified by centrifugation, aliquoted and stored at $-80{ }^{\circ} \mathrm{C}$. They were then analyzed using the RT-qPCR assay as described above. Each experiment was performed in triplicate.

\section{Statistical analyses.}

Exploratory analysis was performed using a two-way ANOVA with a Sidak's test correction. The correlation between CPE and fluorescent-based nAbs titers results was determined using a 
linear regression model in the software Prism 7 (GraphPad). Pearson correlation coefficient $\left(\mathrm{R}^{2}\right)$ and $P$ value are calculated using the default settings in the software Prism 7.00. Statistical analysis and graphical representation were performed using GraphPad Prism 7.00. $P$ values $\leq$ 0.05 were considered statistically significant.

\section{Results}

\section{General strategy for de novo production of $\mathrm{CoVs}$}

From each full-length genome sequence, 8 overlapping subgenomic fragments with an average size of 3,900 nucleotides were designed and de novo synthesized (Figure 1). During de novo synthesis, the human cytomegalovirus promoter (pCMV) was inserted upstream from the first fragment to initiate transcription. The sequence of the hepatitis delta virus ribozyme followed by the simian virus 40 polyadenylation signal (HDR/SV40pA) were added at the 3 ' end of the last fragment to enable transcription termination and RNA maturation (see previous studies ${ }^{19,20}$ ). The synthetic subgenomic viral fragments were used as templates for PCR amplification and transfected into permissive cells and passages 2 times on infected competent cells. Infectious viral particles were successfully obtained after two passages as confirmed by (i) observation of a cytopathic effect (CPE), (ii) measurement of the molecular viral load in cell supernatant medium using a real-time RT-qPCR assay, and (iii) measurement of the infectious viral load in cell supernatant medium using TCID $_{50}$ assays.

\section{Generation of wild-type CoVs}

First, we rescued wild-type infectious particles of the European SARS-CoV-2. At the second passage on VeroE6 cells, extensive CPE was observed from 2 days post-infection (dpi), as also observed with the clinical strain. The production of infectious particles was confirmed by the average molecular load $\left(5.5 \pm 0.4 \log _{10}\right.$ RNA copies per $\left.\mathrm{mL}\right)$ and infectious viral load $(5.5 \pm 0.4$ $\log _{10} \mathrm{TCID}_{50}$ per $\mathrm{mL}$ ) detected at $2 \mathrm{dpi}$ in the cell culture supernatant medium (Table). Replication kinetics were performed to compare the replicative fitness of the clinical and the rescued viruses. Clinical and ISA strains showed similar replication kinetics and no significant difference in molecular viral loads was observed post-infection (pi) ( $N=3$; Two-way ANOVA; $p>0.05)$ (Figure 2a).

We further evaluated the robustness of the ISA method to reconstruct a well-known and widespread felid coronavirus, FeCoV (Supplemental Figure S). After two passages of cell supernatant on FeA cells, extensive CPE was observed. The presence of rescued viral particles 
was confirmed by the average molecular and infectious viral loads at $2 \mathrm{dpi}$ in the cell culture supernatant medium $\left(6.7 \pm /-0.5 \log _{10}\right.$ RNA copies per $\mathrm{mL}$ and $5.8 \pm /-0.6 \log _{10} \mathrm{TCID}_{50}$ per $\mathrm{mL}$, respectively) (Table). Comparative replication kinetics at an MOI of 0.01 did not show significant differences in virus yield (Figure 2b) from 12 hours until the endpoint ( 2 dpi) $(N=$ 3; Two-way ANOVA; $p>0.05$ ) (Figure 2b).

\section{Generation of the D614 SARS-CoV-2 strain}

Early in the SARS-CoV-2 pandemic, several mutations were observed when comparing the original strain from Wuhan and the strain circulating in Europe. Among these mutations, the D614G on the spike protein sequence was suspected to contribute to changing the viral fitness $^{29,30}$. To generate the spike protein D614 coding sequence in the ISA European strain, we substituted the Gly at position 614 of the spike protein sequence in the fragment $n^{\circ} 7$ by an Asp and conducted the ISA method using this de novo synthesized modified DNA fragment (Figure 1). After 5 days post-transfection on BHK-21 and 2 dpi on VeroE6 cells, infectious particles were obtained and confirmed by CPE and molecular and infectious viral loads at 2 dpi in the cell culture supernatant medium (Table). Sequencing of the genomic fragment in which the modification was done indicated that the engineered D614 mutation in the spike protein was maintained after 2 passages in VeroE6 cells. Every $12 \mathrm{~h}$ pi, the molecular viral load in the supernatant medium of infected Vero E6 cells was recorded and analysed. Interestingly, significant differences were observed in early collections, particularly at $12 \mathrm{~h}$ and $24 \mathrm{~h}$ pi where molecular viral loads for the ISA D614 strain was $1.1 \pm /-0.3$ and $2.7 \pm 0.3 \log _{10}$ RNA copies per $\mathrm{mL}$ respectively and $3.1 \pm /-0.2$ and $3.9 \pm 0.2 \log _{10}$ RNA copies per $\mathrm{mL}$ respectively for the ISA European strain (Figure 2a) ( $N=3$; Two-way ANOVA; $p<0.05)$. At the endpoint, no significant difference was observed (48 h pi) between molecular viral loads for ISA D614 and European strains (4.6 $\pm /-0.2$ and $4.7 \pm 0.1 \log _{10}$ RNA copies per mL respectively) ( $N=3$; Two-way ANOVA; $p>0.05)$.

\section{Generation of a fluorescent SARS-CoV-2}

We next engineered a D614 SARS-CoV-2 strain containing a mCherry monomeric red fluorescent protein. The hypothetic dispensable $3 \mathrm{a}_{\text {region }}{ }^{31}$ was removed and replaced by the mCherry protein sequence and de novo synthesized the modified DNA fragment for the ISA procedure (Figure 1). Following the ISA procedure, 5 days post-transfection on BHK-21 or 2 dpi on VeroE6 cells, infectious fluorescent mCherry D614 SARS-CoV-2 strain was recovered and similar cytopathic effect was observed at 48 pi. At an MOI of 0.05 , red fluorescence was 
readily detectable in the infected cells at 48 hours pi in comparison to the ISA D614 infected cells (Figure 3). The molecular and infectious viral loads detected at 2 dpi in Vero cell supernatant medium were indicated in Table. Sequencing of the genomic fragment in which the modification was done indicated that the engineered D614 mutation in the spike protein was maintained after 2 passages in VeroE6 cells. The mCherry D614 strain replicative fitness was assessed using the same conditions as previously described and compared with the ISA D614 SARS-CoV-2 strain. Replicative fitness was similar between fluorescent mCherry D614 and ISA D614 strains and no significant difference in molecular viral loads between each strain was recorded at any time pi (Figure 2).

\section{Development and evaluation of neutralization and antiviral assays using the fluorescent mCherry SARS-CoV-2.}

A seroneutralization assay was established by exploiting the fluorescence of the mCherry D614 SARS-CoV-2 for the endpoint readout and this was compared with a reference procedure ${ }^{32}$ using the D614 strain, relying on the manual detection of CPE after image recording of the culture wells. Twenty-three human sera, collected during the COVID-19 pandemic, were tested for neutralization in the assay. Qualitatively, all the sera showing neutralization (18 out of 23) in the standard procedure performed equally well in the fluorescent procedure (Supplemental table 5) and all the negative sera in the CPE-based method were also negative in the fluorescence-based method. Titration of each serum with both methods indicated that seroneutralization titers were significantly correlated throughout the entire range of dilutions ( $p$ $<0.0001)$ with a correlation coefficient $\left(\mathrm{R}^{2}\right)$ of 0.8894 (Figure 4).

We next evaluated the mCherry D614 SARS-CoV-2 strain for an antiviral assay. Remdesivir was used as a reference compound known to inhibit the viral replication in vitro at the $\mu \mathrm{M}$ level ${ }^{25,33}$. The half-maximal effective concentration (EC50) was determined by monitoring the fluorescence in the presence of decreasing concentrations of Remdesivir (Figure 5a). The EC50 was compared to values obtained for both ISA D614 and mCherry D614 strains using a standard procedure relying on the quantification of the viral RNA yield ${ }^{33}$. The EC50 recorded for ISA D614 and mCherry D614 strains by RNA quantification were $1.4 \mu \mathrm{M}$ (Figure 5b) and $0.6 \mu \mathrm{M}$ (Figure 5b) respectively, suggesting that the insertion of the tag made the virus slightly more susceptible to the presence of the drug. The EC50 obtained by measuring the fluorescence of the mCherry D614 strain was in agreement with the EC50 obtained by the standard method (0.7 $\mu \mathrm{M}$ vs $0.6 \mu \mathrm{M}$ ), indicating that fluorescence reflects well the RNA viral load in the antiviral 
assay (Figure 5b). Moreover, these values are also perfectly coherent with the microscopic observations were fluorescence and $\mathrm{CPE}$ inhibition were observed at $1.3 \mu \mathrm{M}$ and $10 \mu \mathrm{M}$ but not at $0.3 \mu \mathrm{M}$ of Remdesivir concentration (Figure $5 \mathrm{c}$ ).

\section{Infection of Syrian hamsters with ISA viruses}

A hamster model was used to study the clinical and virological properties of clinical and ISAconstructed SARS-CoV-2 strains. Groups of 4 animals were infected by intranasal inoculation of $10^{3}$ TCID $_{50}$ of viruses. Clinical monitoring of animals infected by clinical and ISA SARSCoV-2 showed a significant weight loss from 2 dpi when compared to animals inoculated with $0.9 \%$ sodium chloride solution (Two-way ANOVA; $p \leq 0.01$ ). From 0 to $4 \mathrm{dpi}$, infected animals expressed similar normalized weights (Two-way ANOVA; $p \geq 0.05$ ). However, from 5 to $7 \mathrm{dpi}$, animals infected by the clinical European strain or the ISA D614 strain expressed a greater weight loss than those infected with the ISA European SARS-CoV-2 (Two-way ANOVA; $p \leq 0.05$ ) (Figure 6a).

For each strain, viral infection and replication were confirmed as infectious virus was recovered from lungs and viral RNA was detected in lungs and plasma at 3 dpi. Analysis of virus replication in clarified lung homogenates revealed that mean infectious titers (measured using TCID 50 assay) were 6.6, 5.8 and $6.6 \log _{10}$ TCID $50 / g$ of lung, for animals infected with clinical European, ISA European and ISA D614 strains respectively. Infectious titers of virus recovered from hamsters infected by the ISA Wuhan strain were significantly lower than those rescued from hamsters infected with the clinical or the ISA European strains $(p \leq 0.01)$ (Figure 6b). Mean viral RNA yields (measured using quantitative real time RT-PCR assay) were 9.2, 9 and 9.5 $\log _{10}$ copies/g of lung for animals infected with clinical European, ISA European and ISA D614 strains respectively. Viral RNA yields in lungs of hamsters infected by the ISA D614 strain were significantly higher than those of hamsters infected with the clinical European or the ISA European strains $(p \leq 0.05)$ (Figure 6c). Analysis of virus replication in plasmas revealed no significant difference between the three strains $(\mathrm{p} \geq 0.05)$. Mean viral RNA yields (measured using quantitative real time RT-PCR assay) were 3.4, 5.0 and $4.2 \log _{10}$ copies/mL respectively for animals infected with clinical European, ISA European and ISA D614 strains (Figure 6d). 
360

361

362

363

364

365

366

367

368

369

370

371

372

373

374

375

376

377

378

379

380

381

382

383

384

385

386

387

388

389

Reverse genetics methods are valuable modern tools to decipher biological properties of human and animal coronaviruses, mechanisms that underlie viral emergence and adaptation to the host, and to develop therapeutic strategies. Although coronaviruses have the largest genomes of known human RNA viral pathogens, several techniques were developed for the production of infectious clones before the emergence of the COVID-19 pandemic and they have been successfully adapted to the study of SARS-CoV-2 ${ }^{15,16}$. Nevertheless, these techniques rely on the cloning of a full-genome which is a relatively difficult and time-consuming process due to the large size of the coronavirus genome.

The ISA reverse genetics method overcomes this problem because no full length genomic cDNA cloning is involved in this procedure. In addition, the genome sequence of ISA-generated viruses can be identical to that of the targeted virus as no restriction sites or other genomic modifications are required. The method was originally developed for a variety of viruses with relatively short positive-stranded RNA genomes (i.e. $<15,000$ nucleotides) such as flaviviruses, alphaviruses or enteroviruses ${ }^{18-21}$. For these viruses, usually three overlapping subgenomic DNA fragments is sufficient to cover the full length genomic cDNA and to flank the 5' and 3' ends with a transcription start and a ribozyme/polyA signal, respectively. In the case of the much larger $\mathrm{CoV}$ genome, we found that by setting the number of subgenomic fragments to 8 , the ISA method could be used to produce a wild-type and genetically modified CoV.

However, the recombination in cellula of such a high number of fragments had never been evaluated earlier. The objective therefore, was to assess whether or not we had reached the technical limitations of the method. Full length cDNA reconstitution implies two constraints: that cells generating infectious RNA should receive all fragments covering the entire virus genome, and that all fragments recombine together. An obvious consequence of this procedure is that the probability for an individual cell to receive all subgenomic fragments simultaneously upon transfection decreases when the number of fragments increases. Accordingly, in order to integrate the stochastic aspect of viral genesis in the ISA process, transfection/infection experiments can be conveniently performed in 96-well tissue culture plates with the product of $30 \mu \mathrm{g}$ of mixed PCR fragments obtained from one single PCR reaction for each fragment.

Mutagenesis within the original sequence fragments can be accomplished using subgenomic sequences without jeopardizing subsequent genomic assembly. The resulting product is 
immediately ready for the ISA procedure which can be exploited to decipher the mechanisms involved in viral evolution, transmission, pathogenesis and virus/host interactions ${ }^{34-40}$.

We firstly designed and de novo synthesized a modified synthetic fragment to generate the G614D mutation in the Spike protein, as observed in the SARS-CoV-2 strain that was isolated in Wuhan, China. In our study, both European and D614 ISA strains displayed similar growth kinetics with similar viral RNA yields detected at the endpoint, suggesting that the D614 mutation does not in fine alter SARS-CoV-2 replicative fitness in VeroE6 cells, as it was previously observed in in another study ${ }^{30}$.

The utilization of tagged viruses for neutralization or antiviral assays has been widely promoted as the presence of a reporter sequence enables direct monitoring of virus replication ${ }^{41,42}$. Viruses that incorporate a reporter tag can be valuable tools to characterize small molecules or nAbs that may inhibit virus replication, as the virus load can be monitored directly without the need for endpoint quantification of released genetic or infectious material. They can thus be used to improve and facilitate the process of seroneutralization assays or in vitro antiviral screening. In this study, an exogenous sequence such as the mCherry fluorescent reporter was stably inserted in the viral genome and enabled rescue of the tagged fluorescent virus. In vitro assays of the mCherry fluorescent strain on a panel of COVID-19 positive and negative human sera or against the antiviral drug, Remdesivir, demonstrated identical results with the wild-type strain. These procedures therefore open up new opportunities to implement robust and straight forward platforms for high throughput and low-cost sero-epidemiological studies. In line with the seroneutralization assay, the mCherry virus can also be confidently used for antiviral screening and EC50 determination of antiviral compounds.

It is well established that golden Syrian hamsters provide a relevant animal model with which to study SARS-CoV-2 infection, pathogenesis and transmission ${ }^{43}$. In our study, both clinical and rescued SARS-CoV-2 strains replicated efficiently in infected hamsters and induced significant clinical symptoms. Interestingly, a lower weight loss associated with a lower infectious viral titer was observed with the ISA European SARS-CoV-2 infected group of animals in comparison with the clinical European strain. Similar results have been observed with Tick-borne ${ }^{44,45}$ and it is recognized that clinical strains, often acting as quasispecies, are better adapted to their ${ }^{46}$ environnement in comparison to clonal or quasi-clonal viruses. Here, it is assumed that the lower virulence of the ISA European SARS-CoV-2 in vivo could originate from a viral adaptation with generation of quasispecies and mutant spectrum. 
422 In conclusion, we report an original and rapid reverse genetic procedure suitable for rescuing 423 infectious coronaviruses under relatively simple operating conditions. The method was shown 424 to be suitable for the de novo rescue of wild-type viruses and for the generation of mutated or 425 engineered viruses. This unique and simplified reverse genetics method has the potential to 426 accelerate significantly our comprehension of human and animal coronavirus pathogenesis, 427 epidemiology, immunology and evolution. Moreover, it could also facilitate the further 428 development of therapeutic and vaccine strategies. 
431 Supplementary Data are provided online.

\section{Acknowledgments}

433 We thank Camille Placidi-Italia, Sarah Attoumani, Magali Gilles, Mariela Saba and Gregory 434 Moureau for assistance in the experimental work. We kindly thanks Pr. Ernest Gould for 435 reviewing this manuscript.

\section{$436 \quad$ Funding}

437 This work was supported by the European Virus Archive Global (EVA GLOBAL) funded by 438 the European Union's Horizon 2020 research and innovation programme under grant agreement 439 No 871029, the Fondation de France "call FLASH COVID-19", project TAMAC and the 440 Inserm through the REACTing (REsearch and ACTion targeting emerging infectious diseases) 441 initiative.

442 Conflict of interest statement. None declared. 
444

445

446

447

448

449

450

451

452

453

454

455

456

457

458

459

460

461

462

463

464

465

466

467

468

\section{References}

1. Zhou, P. et al. A pneumonia outbreak associated with a new coronavirus of probable bat origin. Nature 579, 270-273 (2020).

2. Zhu, N. et al. A Novel Coronavirus from Patients with Pneumonia in China, 2019. N. Engl. J. Med. 382, 727-733 (2020).

3. Korber, B. et al. Spike mutation pipeline reveals the emergence of a more transmissible form of SARS-CoV-2. http://biorxiv.org/lookup/doi/10.1101/2020.04.29.069054 (2020) doi:10.1101/2020.04.29.069054.

4. Kmec, L. Transmission of SARS-CoV-2 on mink farms between humans and mink and back to humans. $11(2020)$.

5. Wise, J. Covid-19: New coronavirus variant is identified in UK. BMJ m4857 (2020) doi:10.1136/bmj.m4857.

6. Voloch, C. M. et al. Genomic characterization of a novel SARS-CoV-2 lineage from Rio de Janeiro, Brazil. http://medrxiv.org/lookup/doi/10.1101/2020.12.23.20248598 (2020) doi:10.1101/2020.12.23.20248598.

7. Tegally, H. et al. Emergence and rapid spread of a new severe acute respiratory syndrome-related coronavirus 2 (SARS-CoV-2) lineage with multiple spike mutations in South Africa.

http://medrxiv.org/lookup/doi/10.1101/2020.12.21.20248640 (2020) doi:10.1101/2020.12.21.20248640.

8. Weisblum, Y. et al. Escape from neutralizing antibodies by SARS-CoV-2 spike protein variants. eLife 9, e61312 (2020).

9. Stobart, C. \& Moore, M. RNA Virus Reverse Genetics and Vaccine Design. Viruses 6, 2531-2550 (2014).

10. Almazán, F. et al. Coronavirus reverse genetic systems: Infectious clones and replicons. Virus Res. $189,262-270$ (2014). 
11. Yang, C.-C. et al. A Novel Dengue Virus Inhibitor, BP13944, Discovered by High-Throughput Screening with Dengue Virus Replicon Cells Selects for Resistance in the Viral NS2B/NS3 Protease. Antimicrob. Agents Chemother. 58, 110-119 (2014).

12. Thiel, V., Herold, J., Schelle, B. \& Siddell, S. G. Infectious RNA transcribed in vitro from a cDNA copy of the human coronavirus genome cloned in vaccinia virus. 9 (2017).

13. Almazan, F. et al. Engineering the largest RNA virus genome as an infectious bacterial artificial chromosome. Proc. Natl. Acad. Sci. 97, 5516-5521 (2000).

14. Yount, B., Curtis, K. M. \& Baric, R. S. Strategy for Systematic Assembly of Large RNA and DNA Genomes: Transmissible Gastroenteritis Virus Model. J. Virol. 74, 10600-10611 (2000).

15. Thi Nhu Thao, T. et al. Rapid reconstruction of SARS-CoV-2 using a synthetic genomics platform. Nature 582, 561-565 (2020).

16. Xie, X. et al. An Infectious cDNA Clone of SARS-CoV-2. Cell Host Microbe 27, 841-848.e3 (2020).

17. Atieh, T., Baronti, C., de Lamballerie, X. \& Nougairède, A. Simple reverse genetics systems for Asian and African Zika viruses. Sci. Rep. 6, 39384 (2016).

18. Atieh, T. et al. New reverse genetics and transfection methods to rescue arboviruses in mosquito cells. Sci. Rep. 7, 13983 (2017).

19. Aubry, F. et al. Single-stranded positive-sense RNA viruses generated in days using infectious subgenomic amplicons. J. Gen. Virol. 95, 2462-2467 (2014).

20. Aubry, F. et al. "ISA-Lation" of Single-Stranded Positive-Sense RNA Viruses from Non-Infectious Clinical/Animal Samples. PLOS ONE 10, e0138703 (2015).

21. Touret, F. et al. Phylogenetically based establishment of a dengue virus panel, representing all available genotypes, as a tool in dengue drug discovery. Antiviral Res. 168, 109-113 (2019).

22. Pedersen, N. C., Allen, C. E. \& Lyons, L. A. Pathogenesis of feline enteric coronavirus infection. J. Feline Med. Surg. 10, 529-541 (2008).

23. Pedersen, N. C. A review of feline infectious peritonitis virus infection: 1963-2008. J. Feline Med. Surg. 11, 225-258 (2009). 
24. Rothberg, J. M. et al. An integrated semiconductor device enabling non-optical genome sequencing. Nature 475, 348-352 (2011).

25. Touret, F. et al. In vitro screening of a FDA approved chemical library reveals potential inhibitors of SARS-CoV-2 replication. Sci. Rep. 10, 13093 (2020).

26. Driouich, J.-S. et al. Favipiravir antiviral efficacy against SARS-CoV-2 in a hamster model. http://biorxiv.org/lookup/doi/10.1101/2020.07.07.191775 (2020) doi:10.1101/2020.07.07.191775.

27. Ninove, L. et al. RNA and DNA Bacteriophages as Molecular Diagnosis Controls in Clinical Virology: A Comprehensive Study of More than 45,000 Routine PCR Tests. PLOS ONE 6, e16142 (2011).

28. Reed, L. J. \& Muench, H. A simple method of estimating fifty per cent endpoints. Am J Epidemiol. 27, 493-497 (1938).

29. Hou, Y. J. et al. SARS-CoV-2 D614G variant exhibits efficient replication ex vivo and transmission in vivo. Science eabe8499 (2020) doi:10.1126/science.abe8499.

30. Plante, J. A. et al. Spike mutation D614G alters SARS-CoV-2 fitness. Nature (2020) doi:10.1038/s41586-020-2895-3.

31. Yount, B. et al. Severe Acute Respiratory Syndrome Coronavirus Group-Specific Open Reading Frames Encode Nonessential Functions for Replication in Cell Cultures and Mice. J. Virol. 79, 14909-14922 (2005).

32. Gallian, P. et al. Lower prevalence of antibodies neutralizing SARS-CoV-2 in group O French blood donors. Antiviral Res. 181, 104880 (2020).

33. Wang, M. et al. Remdesivir and chloroquine effectively inhibit the recently emerged novel coronavirus (2019-nCoV) in vitro. Cell Res. 30, 269-271 (2020).

34. Coutard, B. et al. The spike glycoprotein of the new coronavirus 2019-nCoV contains a furin-like cleavage site absent in CoV of the same clade. Antiviral Res. 176, 104742 (2020). 
35. Hoffmann, M., Kleine-Weber, H. \& Pöhlmann, S. A Multibasic Cleavage Site in the Spike Protein of SARS-CoV-2 Is Essential for Infection of Human Lung Cells. Mol. Cell 78, 779-784.e5 (2020).

36. Eckerle, L. D. et al. Infidelity of SARS-CoV Nsp14-Exonuclease Mutant Virus Replication Is Revealed by Complete Genome Sequencing. PLoS Pathog. 6, e1000896 (2010).

37. Korber, B. et al. Spike mutation pipeline reveals the emergence of a more transmissible form of SARS-CoV-2. http://biorxiv.org/lookup/doi/10.1101/2020.04.29.069054 (2020) doi:10.1101/2020.04.29.069054.

38. Menachery, V. D. et al. Combination Attenuation Offers Strategy for Live Attenuated Coronavirus Vaccines. J. Virol. 92, 15 (2018).

39. Muth, D. et al. Attenuation of replication by a 29 nucleotide deletion in SARS-coronavirus acquired during the early stages of human-to-human transmission. Sci. Rep. 8, (2018).

40. Wang, J.-M., Wang, L.-F. \& Shi, Z.-L. Construction of a non-infectious SARS coronavirus replicon for application in drug screening and analysis of viral protein function. Biochem. Biophys. Res. Commun. 374, 138-142 (2008).

41. Xie, X. et al. A nanoluciferase SARS-CoV-2 for rapid neutralization testing and screening of antiinfective drugs for COVID-19. Nat. Commun. 11, 5214 (2020).

42. Hou, Y. J. et al. SARS-CoV-2 Reverse Genetics Reveals a Variable Infection Gradient in the Respiratory Tract. Cell 182, 429-446.e14 (2020).

43. Sia, S. F. et al. Pathogenesis and transmission of SARS-CoV-2 in golden hamsters. Nature 583, $834-838$ (2020).

44. de Fabritus, L., Nougair, A. \& de Lamballerie, X. Utilisation of ISA Reverse Genetics and LargeScale Random Codon Re-Encoding to Produce Attenuated Strains of Tick-Borne Encephalitis Virus within Days. PLOS ONE 11 (2016).

45. de Fabritus, L., Nougairède, A., Aubry, F., Gould, E. A. \& de Lamballerie, X. Attenuation of TickBorne Encephalitis Virus Using Large-Scale Random Codon Re-encoding. PLOS Pathog. 11, e1004738 (2015). 

extinction. Virus Res. 107, 129-139 (2005).

548

549 
550 Table. Phenotypic characterization of rescued SARS-CoV-2 and FeCoV. For SARS-CoV-

5512 and FeCoV clinical and ISA strains, cell lines used for transfection and passage, presence or

552 absence of cytopathic effect (CPE), quantification of the viral RNA by real-time RT-qPCR and

553 infectious titers in cell supernatant media (TCID 50 assay) after 2 passages were summarized.

554 Each experiment was performed in triplicate $(N=3)$. The infectious TCID 50 titer was expressed

555 as $\log 10 \mathrm{TCID}_{50} / \mathrm{mL}$ and the amount of RNA copies was expressed as $\log 10$ copies $/ \mathrm{mL}$.

556

557

\begin{tabular}{|c|c|c|c|c|c|c|}
\hline & & \multicolumn{2}{|c|}{ Cell line } & \multirow[t]{2}{*}{ CPE } & \multirow[t]{2}{*}{ Amount of viral RNA } & \multirow[t]{2}{*}{ Infectious titers } \\
\hline & & Transfection & Passage & & & \\
\hline \multirow{4}{*}{ SARS-CoV-2 } & Clinical European & - & VeroE6 & Yes & $7.1+/-0.2$ & $7.6+/-0.1$ \\
\hline & ISA European & BHK-21 + VeroE6 & VeroE6 & Yes & $5.5+/-0.4$ & $5.5+/-0.4$ \\
\hline & ISA D614 & BHK-21 + VeroE6 & VeroE6 & Yes & $6.8+/-0.5$ & $6.0+/-0.2$ \\
\hline & mCherry ISA D614 & BHK-21 + VeroE6 & VeroE6 & Yes & $5.6+/-0.2$ & $5.8+/-0.4$ \\
\hline \multirow{2}{*}{ FeCoV } & Clinical & - & $\mathrm{FeA}$ & Yes & $7.6+/-0.2$ & $7.2+/-0.2$ \\
\hline & ISA & $\mathrm{BHK}-21+\mathrm{FeA}$ & $\mathrm{FeA}$ & Yes & $6.7+/-0.5$ & $5.8+/-0.6$ \\
\hline
\end{tabular}

558

559

560 

was used to design eight overlapping subgenomic viral fragments covering the complete genome. Positions on the genome (in nucleotide) are indicated in bold red.

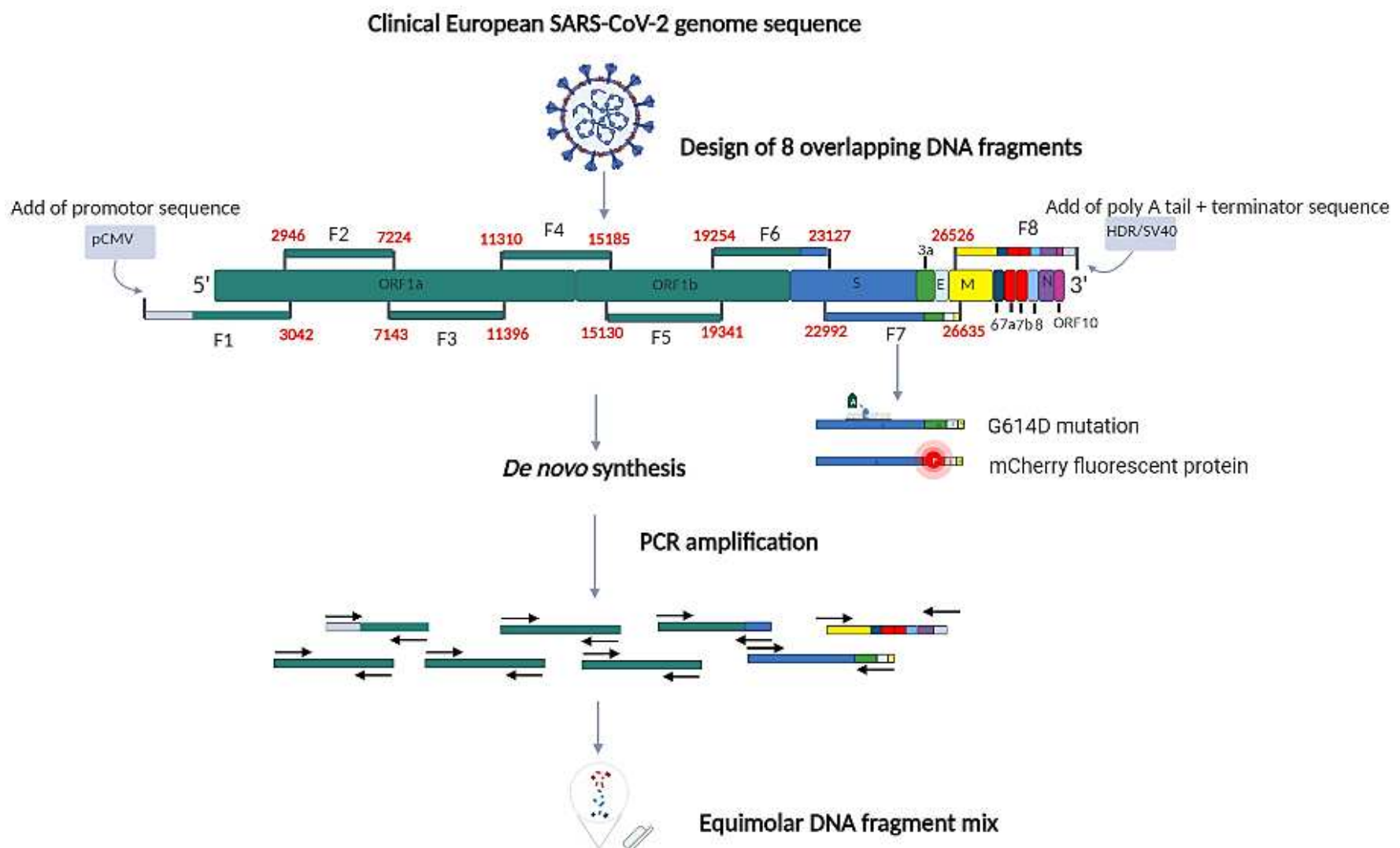


566 Figure 2. Virus replication kinetics of clinical and ISA strains. An MOI of 0.001 and 0.01 were used to infect VeroE6 and FeA cells with rescued or isolated SARS-CoV-2 variants (a)

568 and $\mathrm{FeCoV}$ (b) respectively. Data are represented as mean \pm SD. Each experiment was 569 performed in triplicate $(N=3)$. Exploratory analyses were performed using a two-way ANOVA 570 for multiple comparisons with Sidak's multiple comparisons test.

571 Statistical comparisons were performed between SARS-CoV-2 clinical European vs ISA 572 European strains, ISA European vs ISA D614 strains, ISA D614 vs mCherry D614 strains and 573 between $\mathrm{FeCoV}$ clinical vs ISA strains. Only p-values $\leq 0.05$ were indicated. ***, ** and * 574 symbols indicate that the average value for the ISA D614 strain is significantly different from 575 that of the ISA European strain with p-values $<0.0001,<001$ and $\leq 0.05$ respectively. 
a

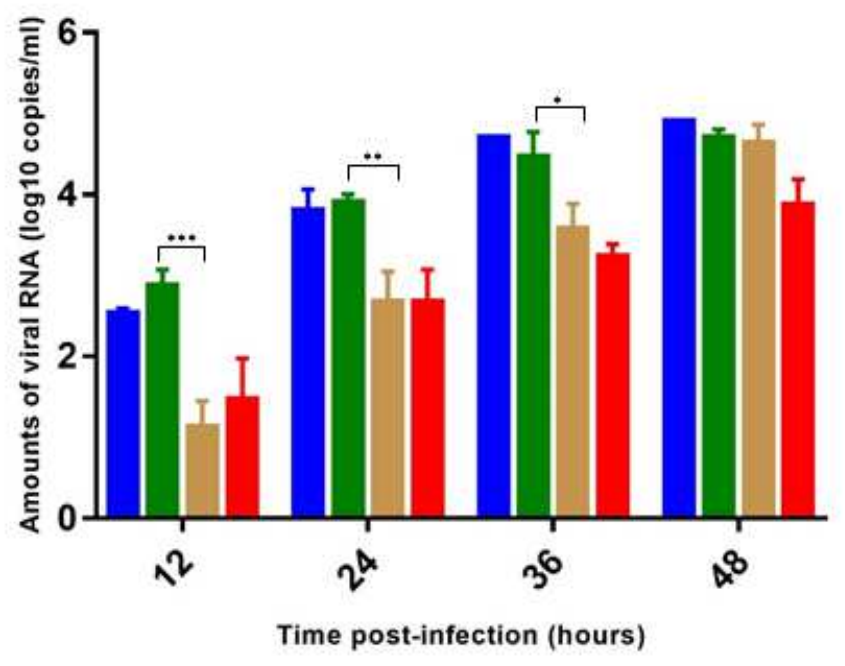

Clinical European strain

SA European strain

ISA D614 strain

mCherry ISA D614 strain

b

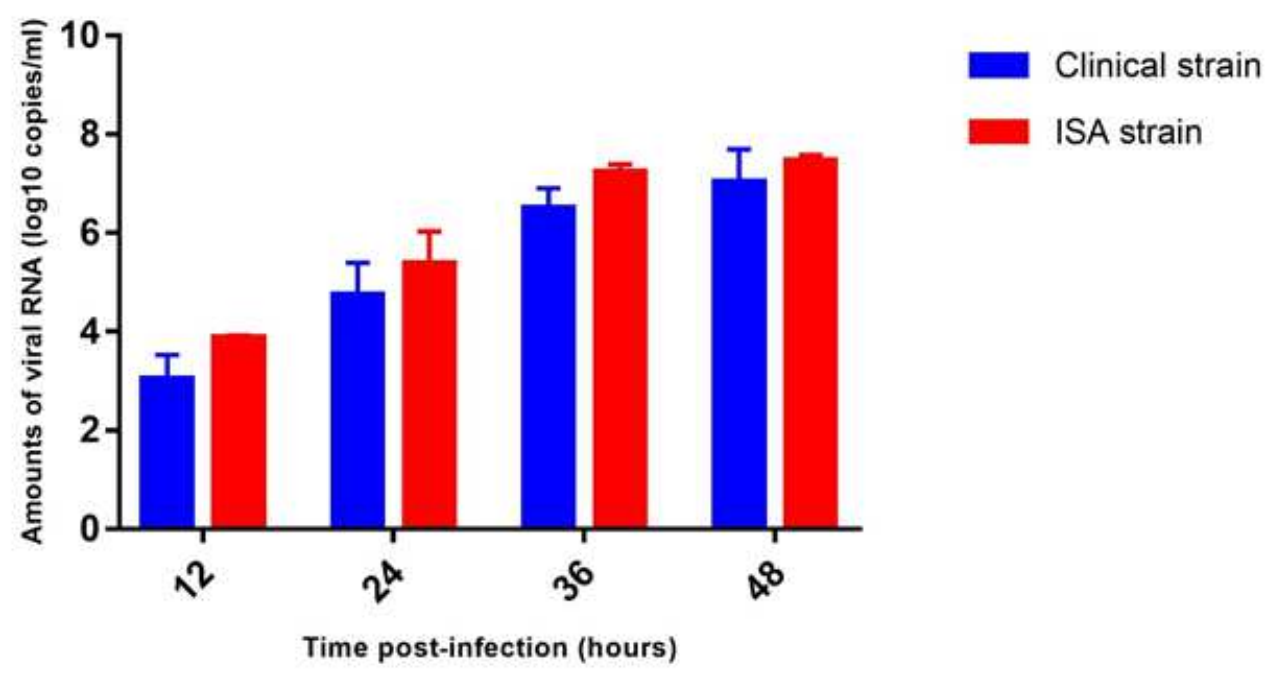




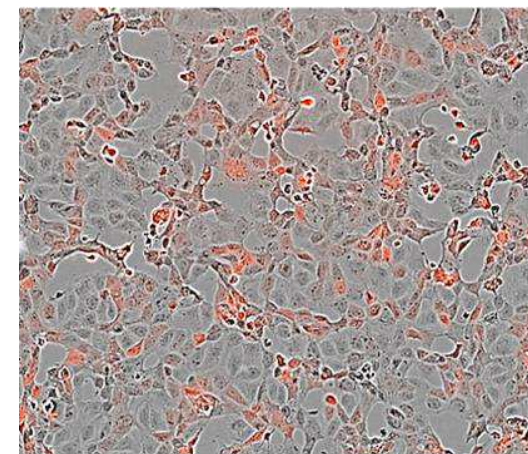

mCherry ISA D614

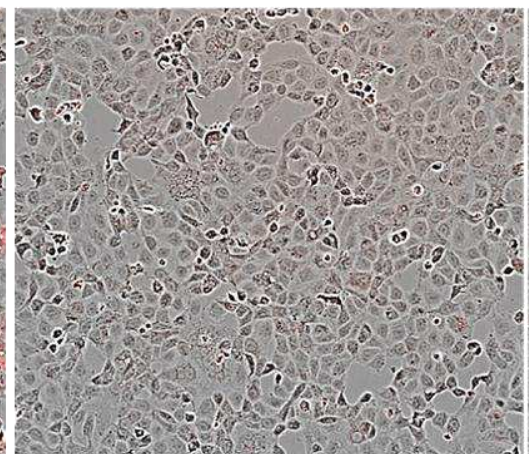

ISA D614 strain

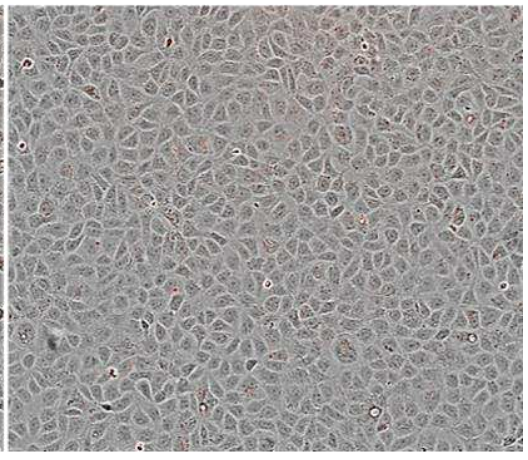

Mock infected 

mCherry D614 SARS-CoV-2 strains. A total of 24 human sera were two-fold diluted and

593 incubated with the ISA D614 and mCherry D614 strains and nAb titers were recorded at 5 days 594 post-infection. $\mathrm{nAb}$ titers were defined as the highest dilution that inhibited the production of 595 distinct CPE with the ISA D614 SARS-CoV-2 or fluorescence with the fluorescent mCherry 596 D614 SARS-CoV-2. For negative samples, an arbitrary value of 10 was assigned (detection 597 threshold for both methods). Each black dot represents results from a given number of sera. 598 Statistical analysis W performed using univariate linear regression. The error band (in grey) 599 represent the $95 \%$ confidence interval of the regression line. The Pearson correlation coefficient 600 $\left(\mathrm{R}^{2}\right)$ and $P$ value analysis are shown.

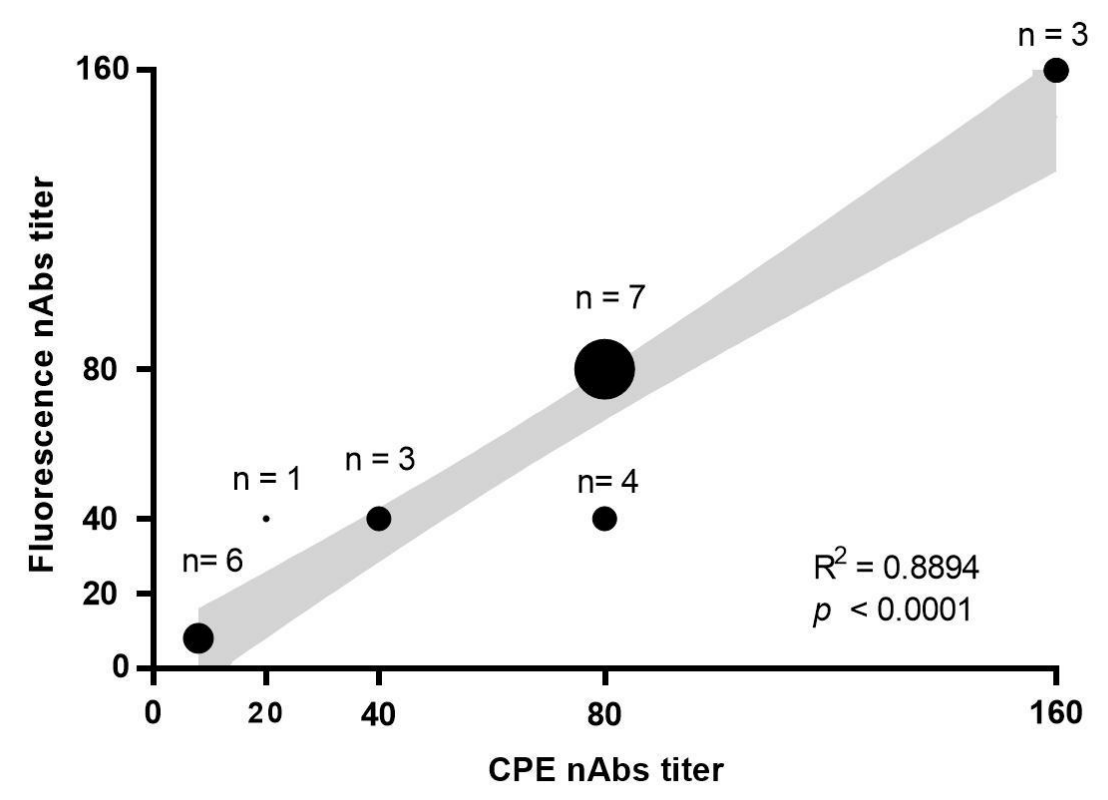

601 


\section{Figure 5. Remdesivir antiviral activity on SARS-CoV-2 in VeroE6 cells.}

603 a: Dose response curve for the ISA D614 and for the mCherry D614 strains obtained by 604 fluorescence or viral RNA measurement in VeroE6 cells; b: Table of EC50 values obtained for 605 the two different strains; c: Fluorescence of the SARS-CoV-2 mCherry in VeroE6 cells with 606 different Remdesivir concentration. EC50: 50\% inhibition, Remdesivir concentrations are 607 presented in log scale for logarithmic interpolation. For the ISA D614 strain values are 608 presented from two independent experiments but graphical representation is from one 609 representative experiment. Dose response curves were generated using GraphPad Prism 610 software version 7.0 (https://graphpad-prism.software.informer.com/7.0/).

611

a

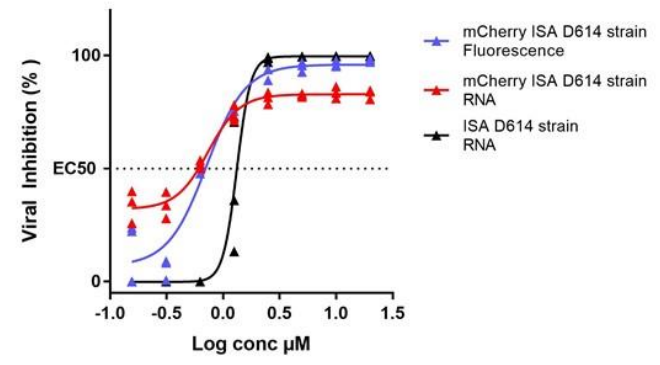

b

\begin{tabular}{|c|c|c|c|}
\hline \multirow[b]{2}{*}{$\mu \mathrm{M}$} & \multicolumn{2}{|c|}{ mCherry ISA D614 strain } & ISA D614 strain \\
\hline & Viral RNA & Fluorescence & Viral RNA \\
\hline EC50 & 0,6 & 0,7 & $1,4 \pm 0,1$ \\
\hline
\end{tabular}

C

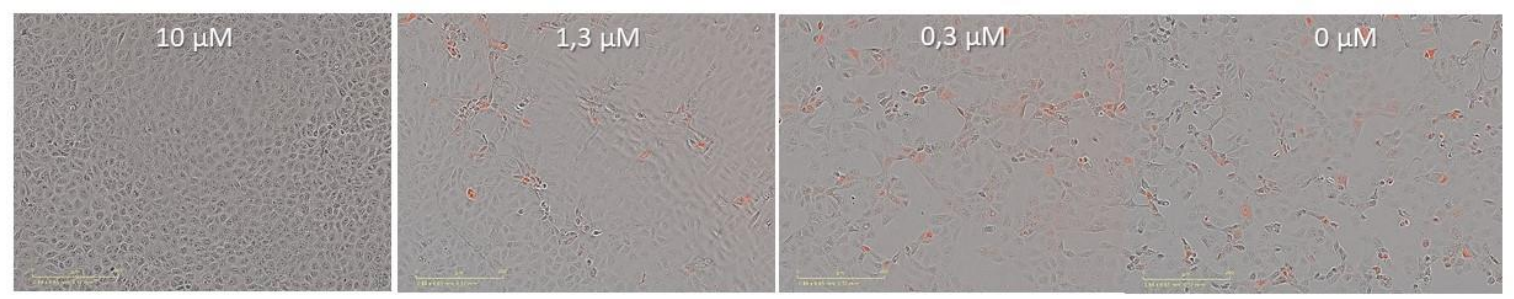




\section{CoV-2 in Syrian gold hamsters.}

615 Groups of 4 hamsters were intranasally infected with $10^{3}$ TCID $_{50}$ of clinical European, ISA 616 European or ISA Wuhan strain. a) Clinical course of the disease. Normalized weight at day $n$ 617 was calculated as follows: \% of initial weight of the animal at day n. b) Lung infectious titers 618 (measured using a TCID 50 assay) expressed in TCID $_{50} / g$ of lung. c) Lung viral RNA yields 619 (measured using an RT-qPCR assay) expressed in virus genome copy/g of lung. d) Plasma 620 viral loads (measured using an RT-qPCR assay) expressed in viral genome copies/mL of 621 plasma. All graphs represent mean \pm SD. ** and * symbols indicate significant difference with 622 a p-value ranging between 0.001-0.01 and 0.01-0.05 respectively (details in supplemental tables 6237 and 8 ).

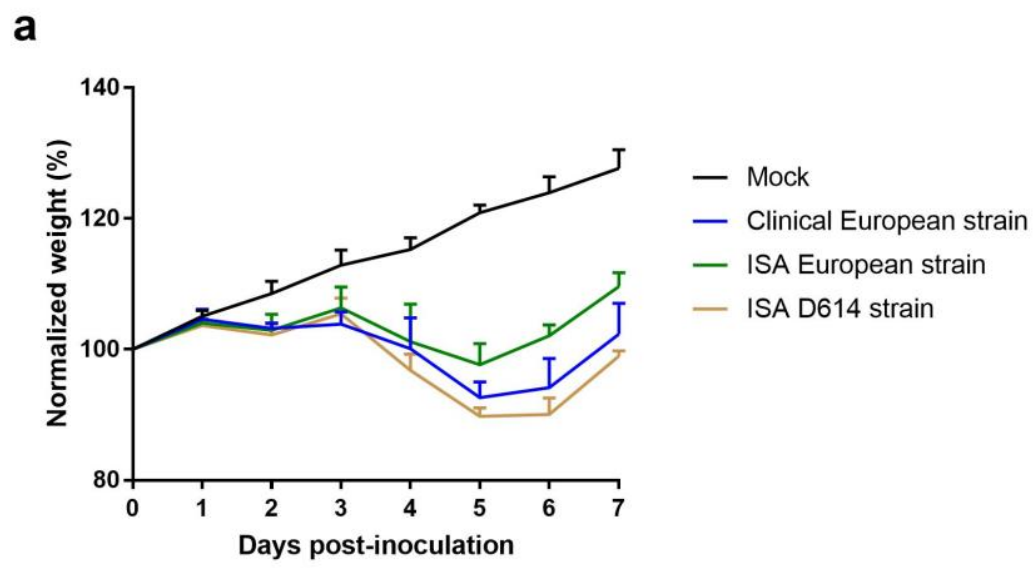

b

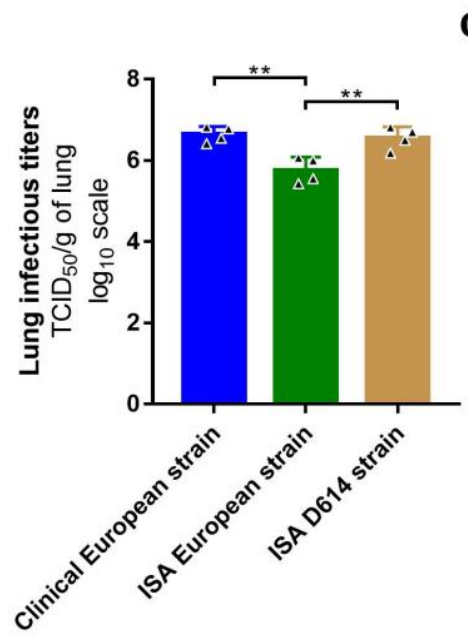

C

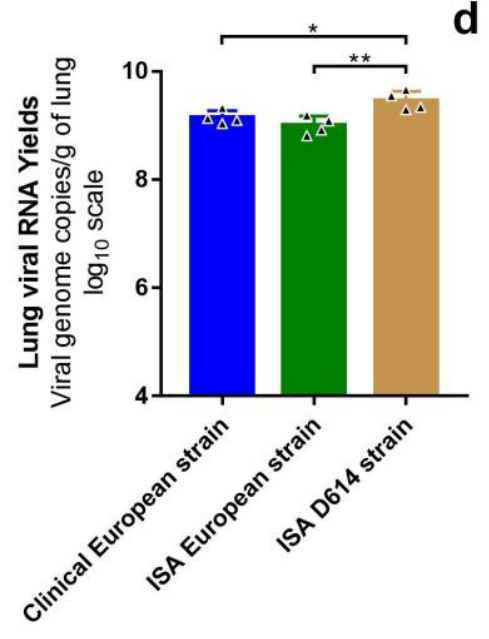

d

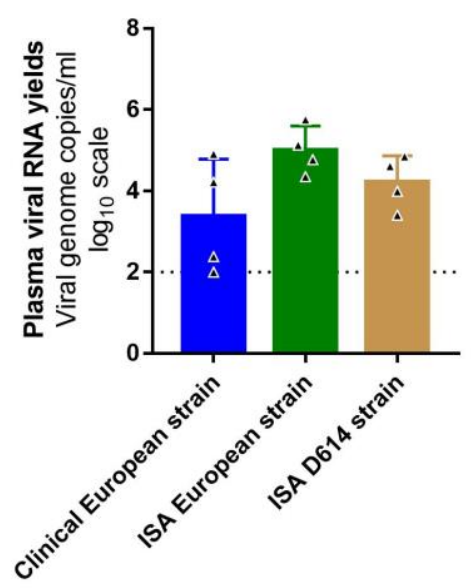


628 Supplemental Table 1. Primers used to amplify cDNA from de novo synthesized fragments.

\begin{tabular}{|c|c|c|c|c|}
\hline Virus & Fragment & Primer Forward & Primer Reverse & Position \\
\hline \multirow{9}{*}{$\begin{array}{l}\text { SARS- } \\
\text { CoV-2 }\end{array}$} & 1 & TCAATATTGGCCATTAGCCATA & GGGTAGAAAGAACAATACATATGTG & start-3042 \\
\hline & & & & \\
\hline & 2 & GCATTGATTTAGATGAGTGGAGTATG & GCAGTTAAATCCCATTTAAAAGATG & $2946-7224$ \\
\hline & 3 & GTGGTTTAGATTCTTTAGACACC & GTGTCCACACTCTCCTAGCACC & $7143-11396$ \\
\hline & 4 & GTGTTATGTATGCATCAGCTG & GTGGCGGCTATTGATTTCAAT & $11310-15185$ \\
\hline & 5 & AGTACTATGACCAATAGACAGTTTC & ACTTTTATCAAAAGCTGGTGTGTGG & $15130-19341$ \\
\hline & 6 & GCTATCTAACCTTAACTTGCC & GCTGGTGCATGTAGAAGTTC & $19254-23127$ \\
\hline & 7 & GCACACCTTGTAATGGTGTTG & GCAAATTGTAGAAGACAAATCC & $22992-26635$ \\
\hline & 8 & GCAGATTCCAACGGTACTATTACC & AATTTCACAAATAAAGCATTTTTTTC & 26526-end \\
\hline \multirow[t]{8}{*}{$\mathrm{FeCoV}$} & 1 & GAATAAGGGCGACACGGAAA & GCATCAGAATCGCTTTTG & start-3291 \\
\hline & 2 & GGGTGTAGAACTTGAAGGCT & GGGTTGTTGCATGGTAGGAA & $3166-6553$ \\
\hline & 3 & GCTGGTTTTTGCATGTTGTC & AAACTAAGAATCATAGCA & $6438-10755$ \\
\hline & 4 & GTGTTTACCAATTTACGGTT & GGCTAGCATAAAACTCTTCA & $10656-15139$ \\
\hline & 5 & GGGTTAAACATCTACAGAAA & AAATAATAATGGTTTACC & $15029-20756$ \\
\hline & 6 & GTATTTTAATAATATAC & ATCTGTTGGTTTTTATTC & $20669-23632$ \\
\hline & 7 & GCAGTAGCAGTACAGGCTAG & ATCATTATTCTTCCGACC & $23562-27105$ \\
\hline & 8 & AAATGGCCACACAGGGAC & CTCAGGGTCAATGCCAGCGC & 27012-end \\
\hline
\end{tabular}

629 
631 Supplemental Table 2. Melting temperature (Tm) of primers during synthetic fragments 632 amplification.

633

\begin{tabular}{|c|c|c|}
\hline Virus & Fragment & $\operatorname{Tm}\left({ }^{\circ} \mathbf{C}\right)$ \\
\hline \multirow[t]{8}{*}{ SARS-CoV-2 } & 1 & 55 \\
\hline & 2 & 55 \\
\hline & 3 & 55 \\
\hline & 4 & 61 \\
\hline & 5 & 60 \\
\hline & 6 & 57 \\
\hline & 7 & 60 \\
\hline & 8 & 60 \\
\hline \multirow[t]{8}{*}{$\mathrm{FeCoV}$} & 1 & 60 \\
\hline & 2 & 58 \\
\hline & 3 & 56 \\
\hline & 4 & 58 \\
\hline & 5 & 55 \\
\hline & 6 & 55 \\
\hline & 7 & 58 \\
\hline & 8 & 58 \\
\hline
\end{tabular}


640
Supplemental Table 3. Cell lines for which transfections had been attempted to rescue SARSCoV-2 and FeCoV. Transfections were performed either on one cell line, (condition 1) two cell lines (condition 2) or one cell line with addition of a second cell line 24 hours after transfection (condition 3).

\begin{tabular}{|c|c|c|c|c|c|}
\hline \multirow[t]{2}{*}{ Virus } & \multirow{2}{*}{$\begin{array}{c}\text { Condition } 1 \\
\text { Cell line }\end{array}$} & \multicolumn{2}{|c|}{ Condition 2} & \multicolumn{2}{|c|}{ Condition 3} \\
\hline & & Cell line 1 & Cell line 2 & Cell line 1 & Cell line 2 \\
\hline \multirow[t]{12}{*}{ SARS-CoV-2 } & BHK-21 & BHK-21 & VeroE6 & BHK-21 & VeroE6 \\
\hline & & BHK-21 & BGM & & \\
\hline & & BHK-21 & A549 & & \\
\hline & & BHK-21 & Huh7 & & \\
\hline & HEK-293 & HEK-293 & VeroE6 & HEK-293 & VeroE6 \\
\hline & & HEK-293 & BGM & & \\
\hline & & HEK-293 & A549 & & \\
\hline & & HEK-293 & Huh7 & & \\
\hline & BGM & BGM & A549 & & \\
\hline & & & Huh7 & & \\
\hline & A549 & A549 & Huh7 & & \\
\hline & Huh7 & & & & \\
\hline \multirow[t]{17}{*}{$\mathrm{FeCoV}$} & BHK-21 & BHK-21 & $\mathrm{FeA}$ & & \\
\hline & & BHK-21 & $\mathrm{Few}$ & & \\
\hline & & BHK-21 & A-72 & & \\
\hline & & BHK-21 & $\mathrm{FeA}$ & & \\
\hline & HEK-293 & HEK-293 & $\mathrm{FeA}$ & & \\
\hline & & HEK-293 & AK-D & & \\
\hline & & HEK-293 & Fcw & & \\
\hline & & HEK-293 & A-72 & & \\
\hline & & HEK-293 & $\mathrm{FeA}$ & & \\
\hline & SW-13 & SW-13 & $\mathrm{FeA}$ & & \\
\hline & & SW-13 & AK-D & & \\
\hline & & SW-13 & $\mathrm{Fcw}$ & & \\
\hline & & SW-13 & A-72 & & \\
\hline & & SW-13 & $\mathrm{FeA}$ & & \\
\hline & $\mathrm{FeA}$ & & & & \\
\hline & Few & & & & \\
\hline & A-72 & & & & \\
\hline
\end{tabular}


641 Supplemental Table 4. Primers and probes used for real time RT-qPCR.

642

Length (bp)

Primer Forward

Probe

Primer Rev

61

GGCCGCAAATTGCACAAT

CCCCCAGCGCTTCAGCGTTCT

CCAATGCGCGA

118

GCATGGCTTGCTACGCTCAT

CGCCACCAACGGT

CTCAATCCGGAC

100

CTCTGAGAGCGGCTCTATTGGT

CAGACACGCGGTCCGCTATAACGA

GTTCCCTACAACGA

643 
644 Supplemental Table 5. Neutralizing antibodies (nAb) titers using ISA D614 and

645 mCherry D614 SARS-CoV-2 strains. A total of 24 human sera were two-fold diluted and 646 incubated with the ISA D614 and mCherry D614 strains. nAb titers were recorded at 5 days 647 post-infection. Titers were defined as the highest dilution that inhibited the production of 648 distinct CPE with the ISA D614 SARS-CoV-2 or fluorescence with the fluorescent mCherry 649 D614 SARS-CoV-2.

650

651

\begin{tabular}{|c|c|c|}
\hline & \multicolumn{2}{|c|}{ nAb titers } \\
\hline Sera $n^{\circ}$ & ISA D614 strain & mCherry D614 strain \\
\hline 1 & 40 & 20 \\
\hline 2 & 40 & 40 \\
\hline 3 & 40 & 40 \\
\hline 4 & 40 & 40 \\
\hline 5 & 40 & 80 \\
\hline 6 & 40 & 80 \\
\hline 7 & 40 & 80 \\
\hline 8 & 40 & 80 \\
\hline 9 & 80 & 80 \\
\hline 10 & 80 & 80 \\
\hline 11 & 80 & 80 \\
\hline 12 & 80 & 80 \\
\hline 13 & 80 & 80 \\
\hline 14 & 80 & 80 \\
\hline 15 & 80 & 80 \\
\hline 16 & 160 & 160 \\
\hline 17 & 160 & 160 \\
\hline 18 & 160 & 160 \\
\hline 19 & $\leq 10$ & $\leq 10$ \\
\hline 20 & $\leq 10$ & $\leq 10$ \\
\hline 21 & $\leq 10$ & $\leq 10$ \\
\hline 22 & $\leq 10$ & $\leq 10$ \\
\hline 23 & $\leq 10$ & $\leq 10$ \\
\hline 24 & $\leq 10$ & $\leq 10$ \\
\hline
\end{tabular}


652 Supplemental Figure. The ISA method to rescue FeCoV. FeCoV complete genome

653 sequence was used to design eight overlapping subgenomic viral fragments covering the full

654 genome. Positions on the genome (in nucleotide) are indicated in bold red.

655

656

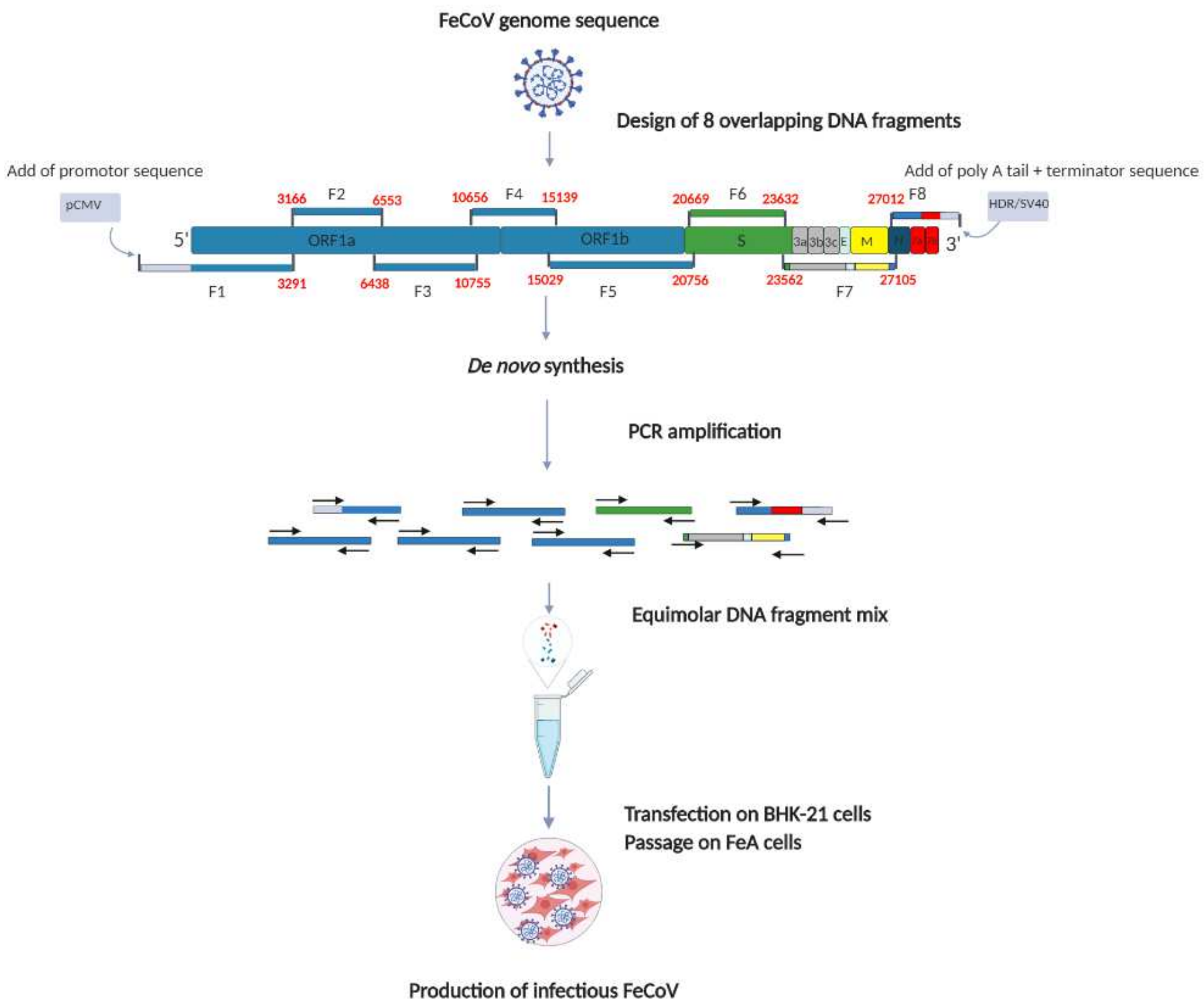

657 


\section{Figures}

\section{Clinical European SARS-CoV-2 genome sequence}
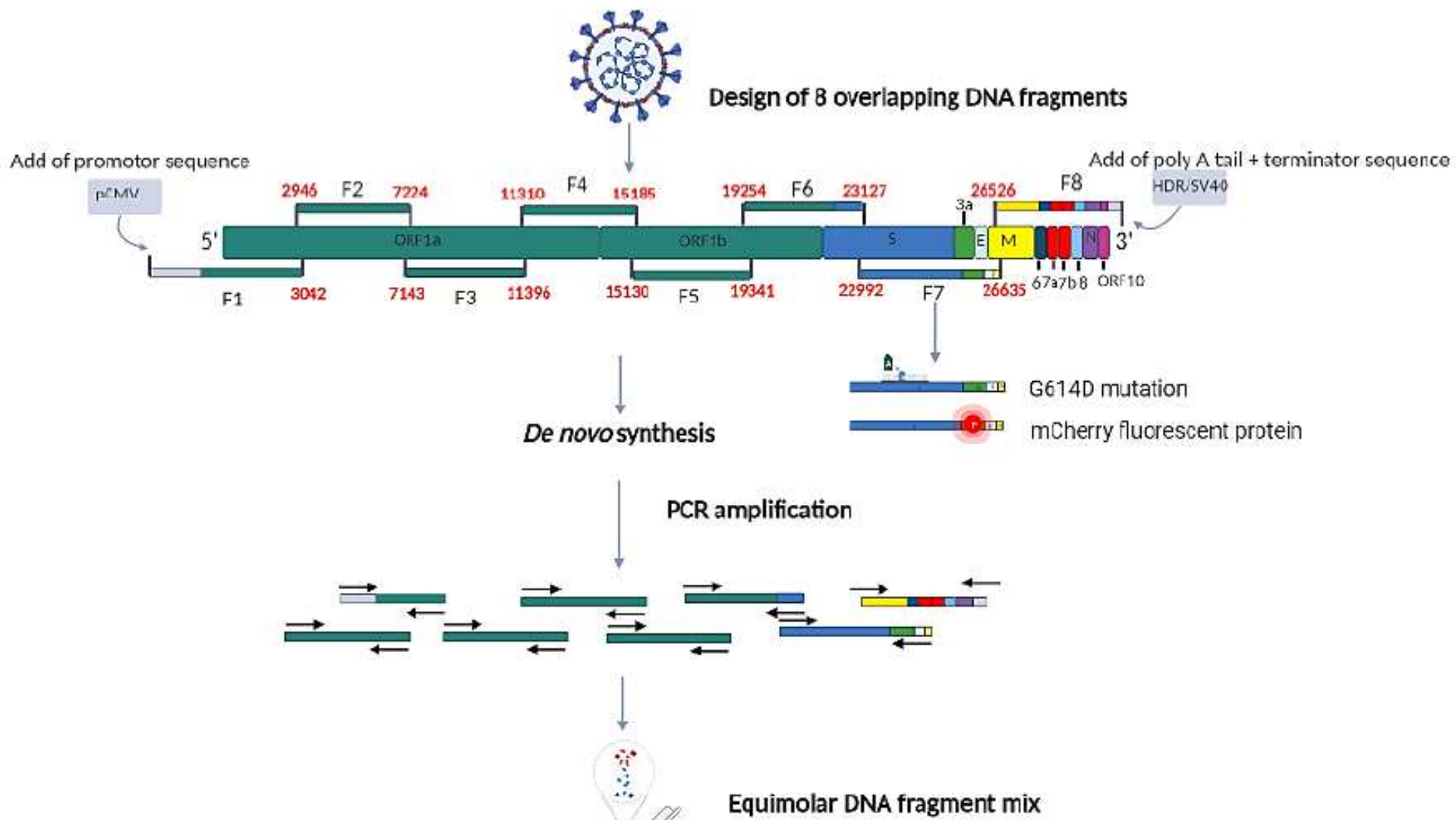

Production of infectious SARS-CoV-2

\section{Figure 1}

The ISA method to rescue SARS-CoV-2. SARS-CoV-2 complete genome sequence was used to design eight overlapping subgenomic viral fragments covering the complete genome. Positions on the genome (in nucleotide) are indicated in bold red. 
a

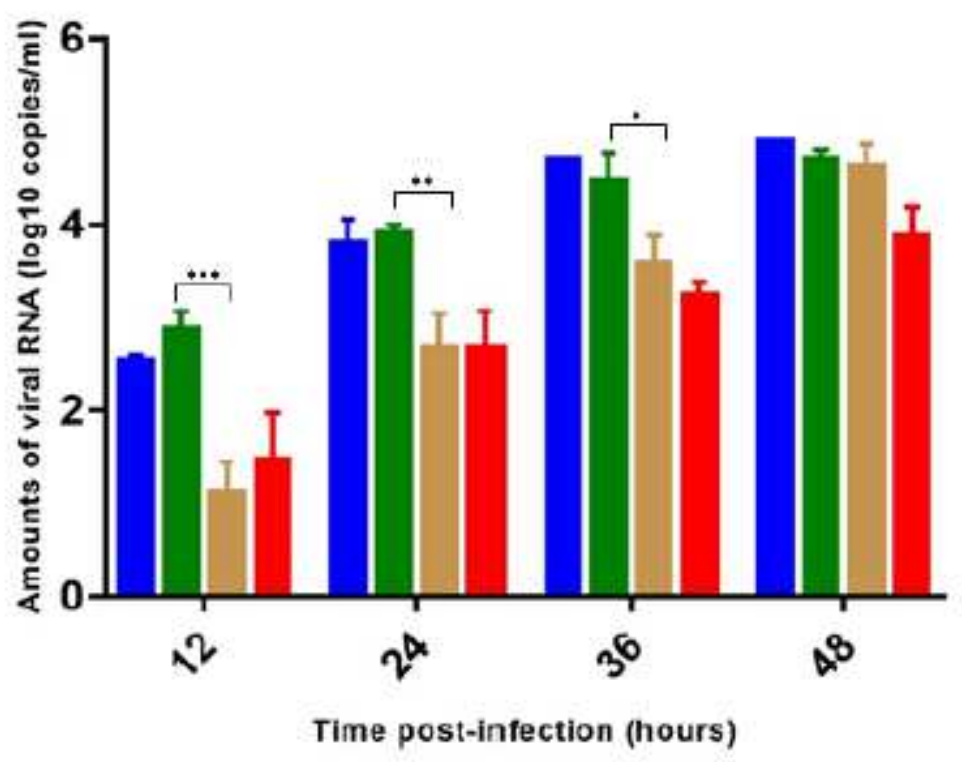

Clinical European strain

SA European strain

ISA D614 strain

mCherry ISA D614 strain

b

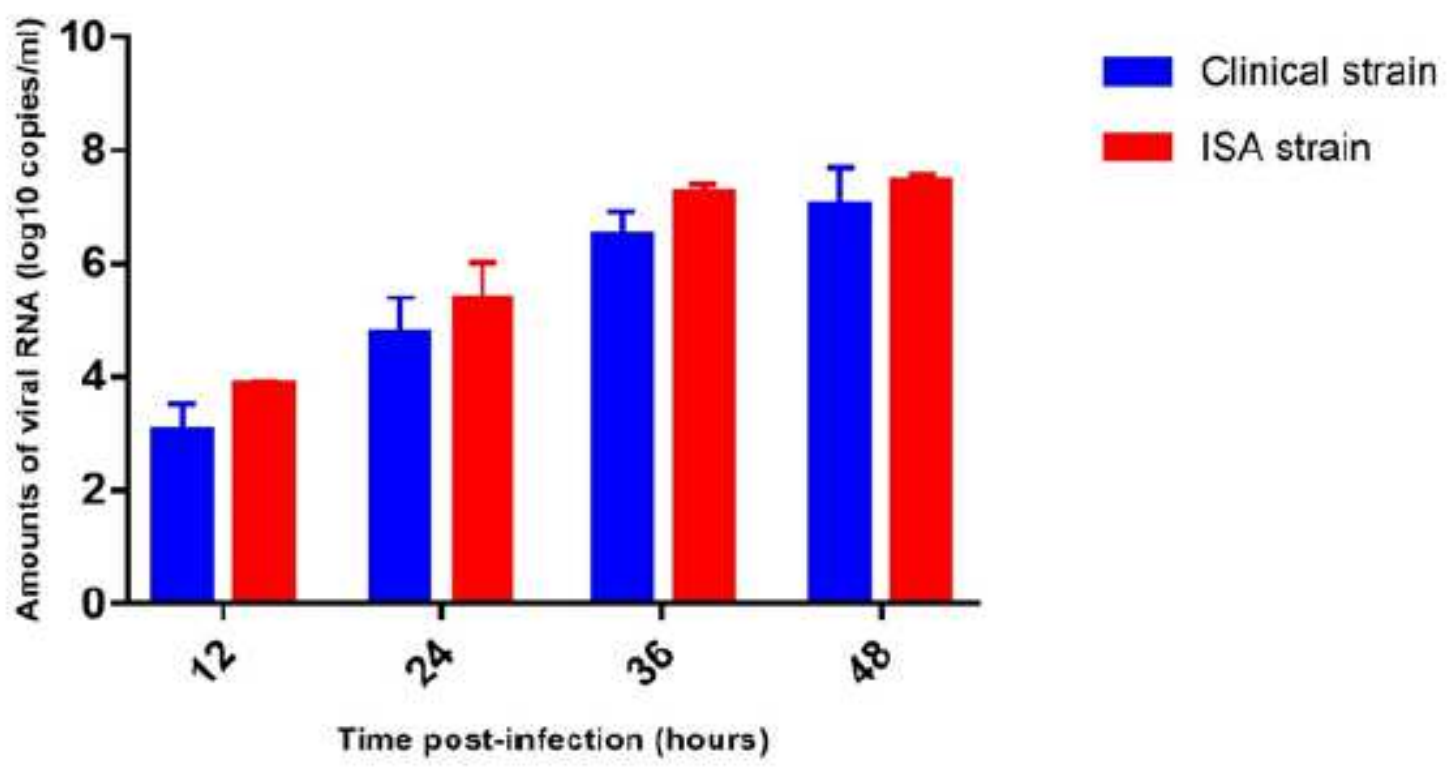

Figure 2

Virus replication kinetics of clinical and ISA strains. An MOI of 0.001 and 0.01 were used to infect VeroE6 and FeA cells with rescued or isolated SARS-CoV-2 variants (a) and FeCoV (b) respectively. Data are represented as mean $\pm S D$. Each experiment was performed in triplicate $(N=3)$. Exploratory analyses were performed using a two-way ANOVA for multiple comparisons with Sidak's multiple comparisons test. Statistical comparisons were performed between SARS-CoV-2 clinical European vs ISA European strains, 
ISA European vs ISA D614 strains, ISA D614 vs mCherry D614 strains and between FeCoV clinical vs ISA strains. Only $p$-values $\leq 0.05$ were indicated. $* \star \star, * \star$ and $*$ symbols indicate that the average value for the ISA D614 strain is significantly different from that of the ISA European strain with $p$-values $<0.0001,<001$ and $\leq 0.05$ respectively.

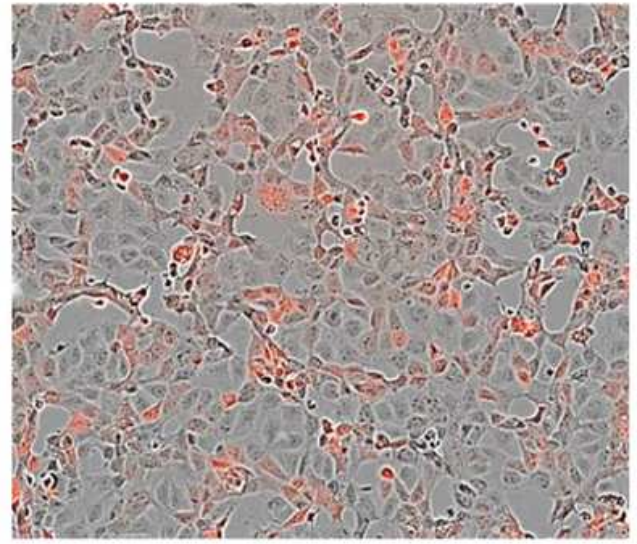

mCherry ISA D614

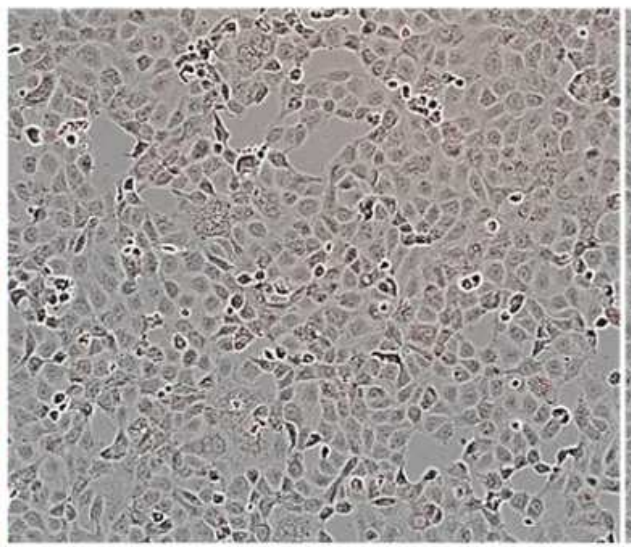

ISA D614 strain

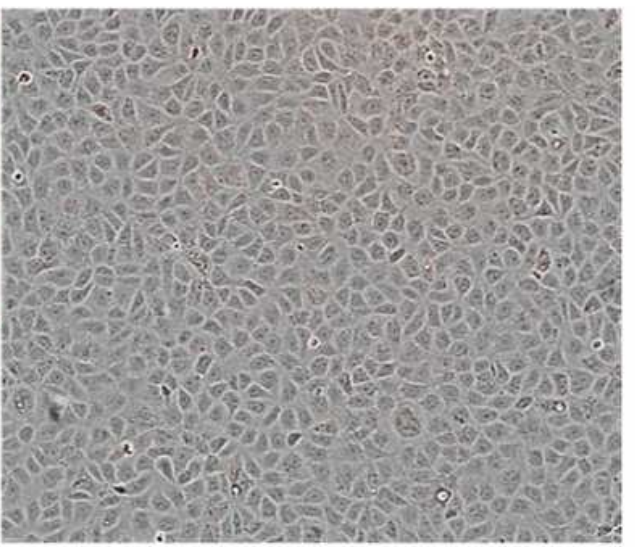

Mock infected

\section{Figure 3}

Fluorescence microscopy analysis of ISA D614 and mCherry D614 strains on VeroE6 infected cells. Vero E6 cells were infected with an MOI of 0.5 with the wild-type ISA D614, fluorescent mCherry D614 strains or mock infected. Pictures were taken at $48 \mathrm{~h}$ pi $(20 \mathrm{x})$. 


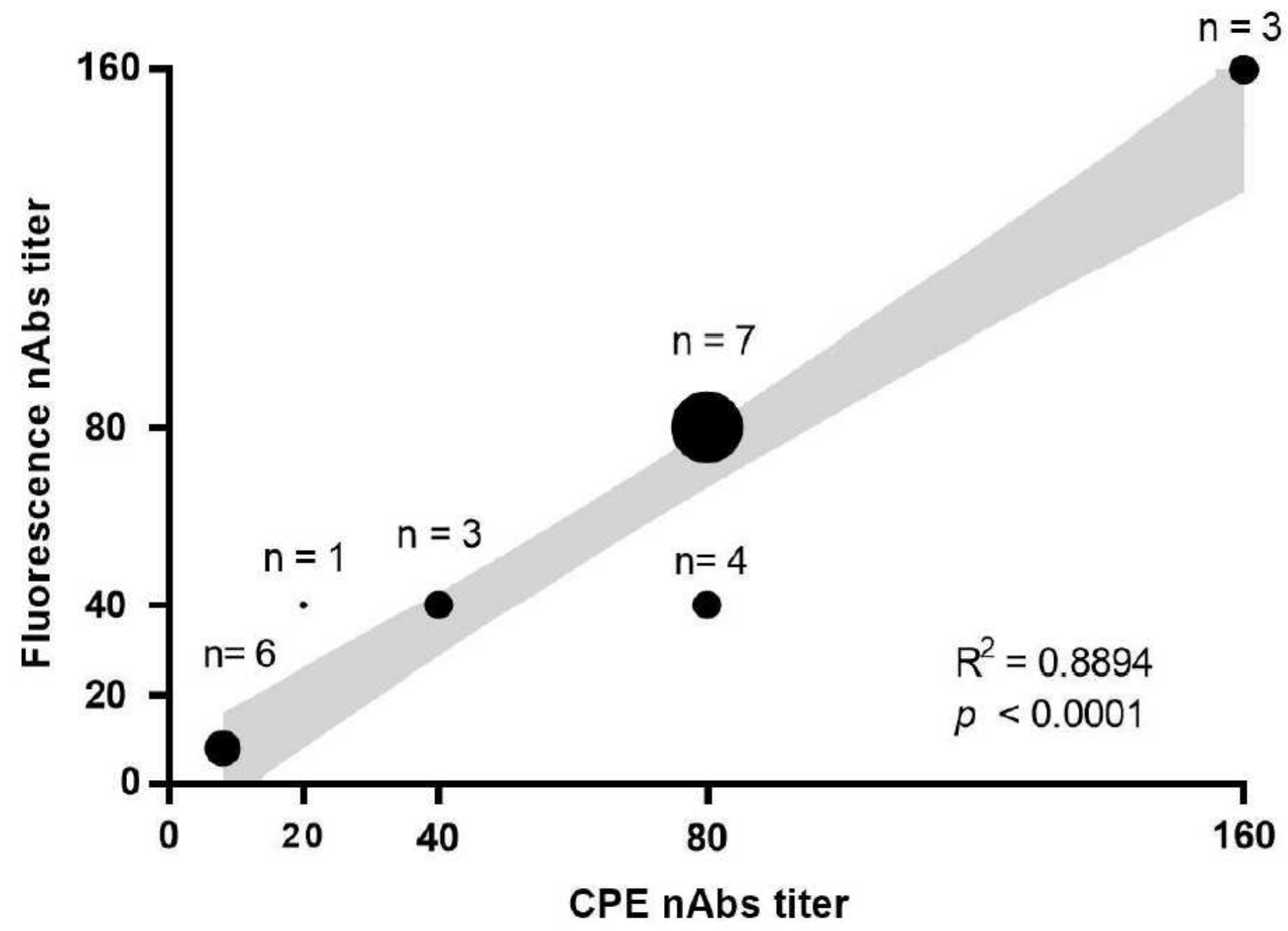

Figure 4

Correlation between neutralizing antibodies (nAbs) titers using ISA D614 and mCherry D614 SARS-CoV-2 strains. A total of 24 human sera were two-fold diluted and incubated with the ISA D614 and mCherry D614 strains and nAb titers were recorded at 5 days post-infection. nAb titers were defined as the highest dilution that inhibited the production of distinct CPE with the ISA D614 SARS-CoV-2 or fluorescence with the fluorescent mCherry D614 SARS-CoV-2. For negative samples, an arbitrary value of 10 was assigned (detection threshold for both methods). Each black dot represents results from a given number of sera. Statistical analysis W performed using univariate linear regression. The error band (in grey) represent the $95 \%$ confidence interval of the regression line. The Pearson correlation coefficient (R2) and P value analysis are shown. 


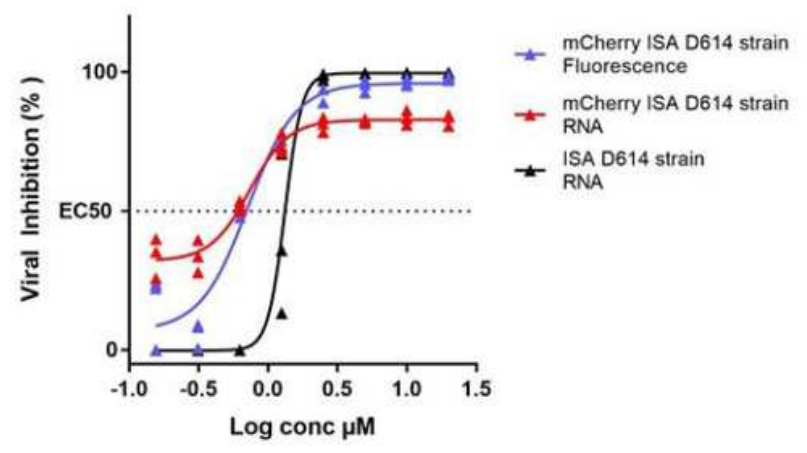

\begin{tabular}{|c|c|c|c|}
\hline \multirow[b]{2}{*}{$\mu \mathrm{M}$} & \multicolumn{2}{|c|}{ mCherry ISA D614 strain } & ISA D614 strain \\
\hline & Viral RNA & Fluorescence & Viral RNA \\
\hline EC50 & 0,6 & 0,7 & $1,4 \pm 0,1$ \\
\hline
\end{tabular}

C
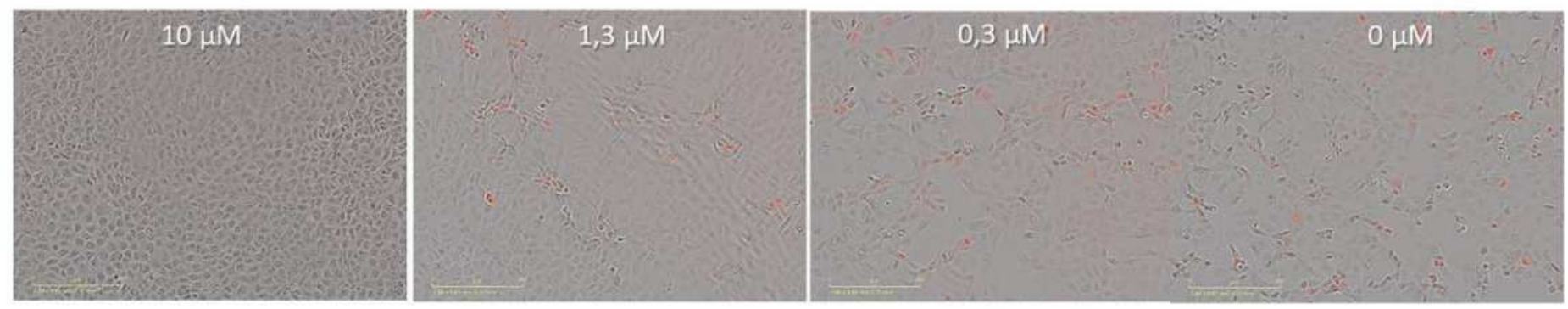

\section{Figure 5}

Remdesivir antiviral activity on SARS-CoV-2 in VeroE6 cells. a: Dose response curve for the ISA D614 and for the mCherry D614 strains obtained by fluorescence or viral RNA measurement in VeroE6 cells; b: Table of EC50 values obtained for the two different strains; c: Fluorescence of the SARS-CoV-2 mCherry in VeroE6 cells with different Remdesivir concentration. EC50: 50\% inhibition, Remdesivir concentrations are presented in log scale for logarithmic interpolation. For the ISA D614 strain values are presented from two independent experiments but graphical representation is from one representative experiment. Dose response curves were generated using GraphPad Prism software version 7.0 (https://graphpadprism.software.informer.com/7.0/). 
a

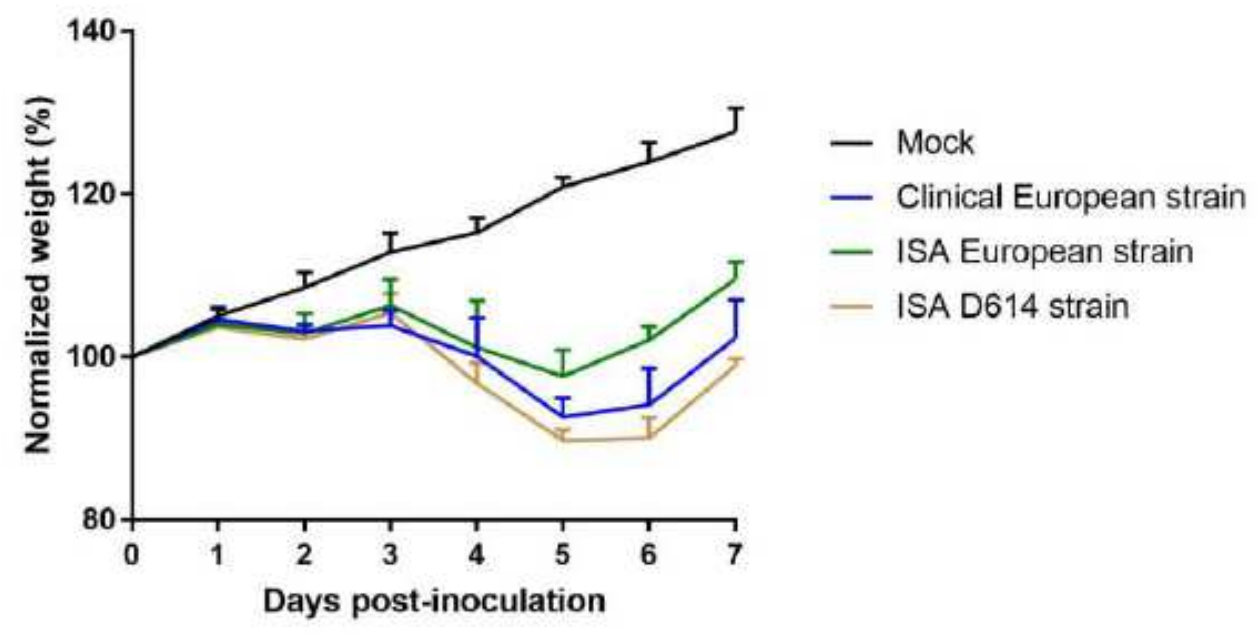

b

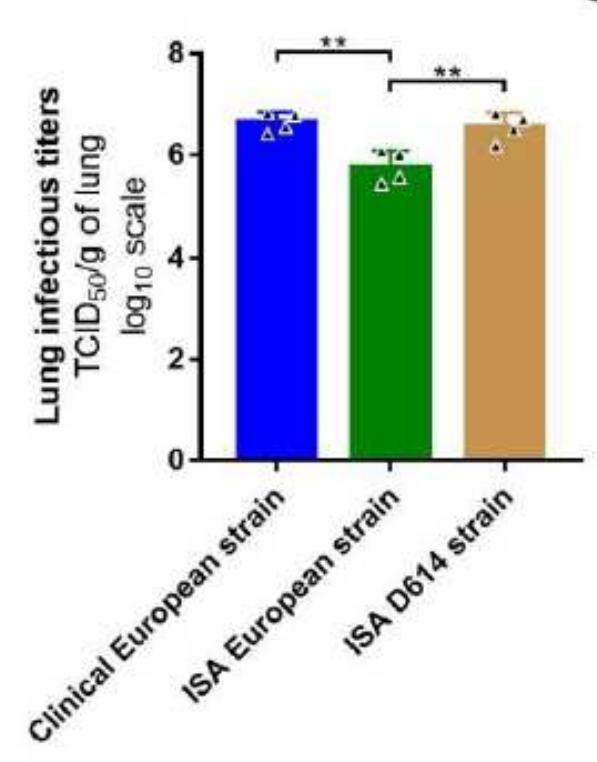

C

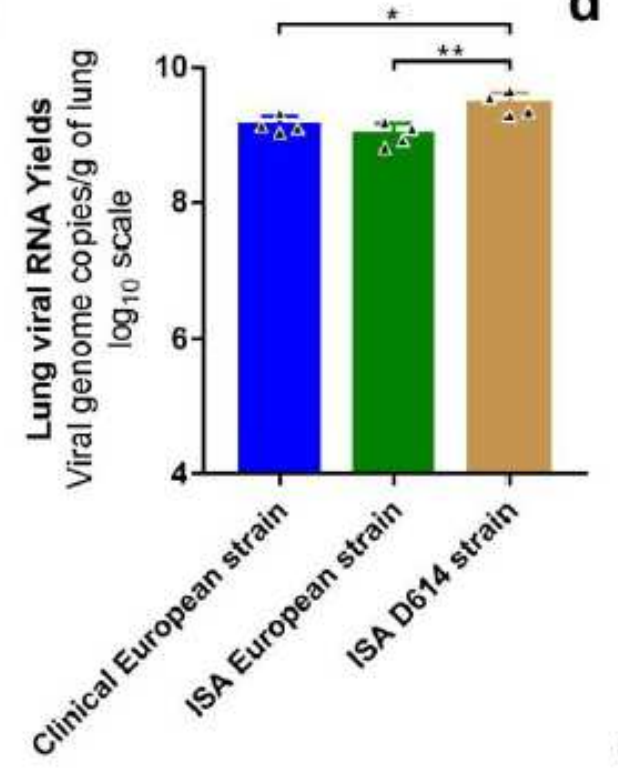

d

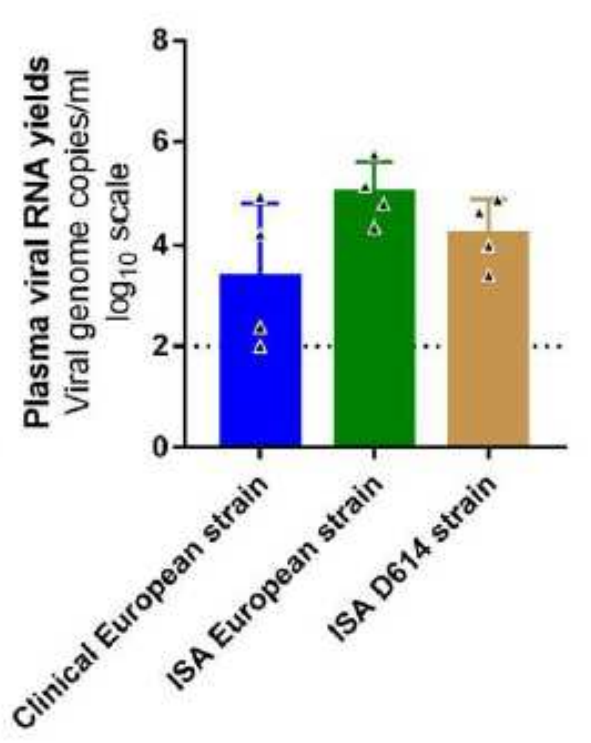

Figure 6

Body weight changes and viral replication CoV-2 in Syrian gold hamsters. Groups of 4 hamsters were intranasally infected with 103 TCID50 of clinical European, ISA European or ISA Wuhan strain. a) Clinical course of the disease. Normalized weight at day $n$ was calculated as follows: $\%$ of initial weight of the animal at day n. b) Lung infectious titers (measured using a TCID50 assay) expressed in TCID50/g of lung. c) Lung viral RNA yields (measured using an RT-qPCR assay) expressed in virus genome copy $/ \mathrm{g}$ of lung. d) Plasma viral loads (measured using an RT-qPCR assay) expressed in viral genome copies $/ \mathrm{mL}$ of plasma. All graphs represent mean $\pm S D$. ** and * symbols indicate significant difference with a $p$-value ranging between 0.001-0.01 and 0.01-0.05 respectively (details in supplemental tables 7 and 8).

\section{Supplementary Files}


This is a list of supplementary files associated with this preprint. Click to download.

- MeladeetalSupplementaryMaterial.pdf 